OPEN ACCESS

Edited by:

David A. Ellis,

University of Bath, United Kingdom

Reviewed by:

Laura Jones,

University College London,

United Kingdom

Nicole Racine,

University of Calgary, Canada

${ }^{*}$ Correspondence:

A. Natisha Nabbijohn anabbijo@uoguelph.ca

Specialty section:

This article was submitted to

Health Psychology,

a section of the journal

Frontiers in Psychology

Received: 13 March 2021

Accepted: 26 August 2021

Published: 01 October 2021

Citation:

Nabbijohn AN, Tomlinson RM, Lee S,

Morrongiello $B A$ and MCMurtry $C M$

(2021) The Measurement and

Conceptualization of Coping

Responses in Pediatric Chronic Pain

Populations: A Scoping Review.

Front. Psychol. 12:680277.

doi: $10.3389 /$ fpsyg.2021.680277

\section{The Measurement and} Conceptualization of Coping Responses in Pediatric Chronic Pain Populations: A Scoping Review

\section{A. Natisha Nabbijohn ${ }^{*}$, Rachel M. Tomlinson ${ }^{1}$, Soeun Lee ${ }^{1}$, Barbara A. Morrongiello ${ }^{1}$ and C. Meghan McMurtry ${ }^{1,2,3}$}

${ }^{1}$ Department of Psychology, University of Guelph, Guelph, ON, Canada, ${ }^{2}$ Pediatric Chronic Pain Program, McMaster Children's Hospital, Hamilton, ON, Canada, ${ }^{3}$ Children's Health Research Institute and Department of Paediatrics, Schulich School of Medicine and Dentistry, London, ON, Canada

Background: Pediatric chronic pain is a prevalent condition that requires significant coping to encourage optimal functioning; however, relevant research is vast, heterogeneous, and difficult to interpret. To date, no attempt has been made to map and summarize the measurement and conceptualization of coping responses in the context of pediatric chronic pain.

Objectives: A scoping review was conducted to map and summarize the participant characteristics, methodologies, theoretical frameworks, and measures used to assess coping responses in youth with chronic pain. The extent to which authors used definitions and examples of coping responses (conceptual clarity) as well as consistently used measures (measurement consistency) and their corresponding conceptualizations (conceptual consistency) relative to how they were intended to be used were assessed.

Methods: Searches were conducted through MEDLINE (PubMed) and PsycINFO. Following title/abstract screening, full-text extractions were performed on 125 English-language publications on coping in youth with chronic pain.

Results: Of the 125 studies, only $12.8 \%$ used a theoretical framework to explain the coping responses assessed, and even fewer (7.2\%) used theory to guide measure selection. Conceptual clarity was rated "low/very low" (i.e., no definitions and/or examples) for $47.2 \%$ of studies. The majority of studies were conducted in the United States $(67 \%)$ and a preponderance of White and female participants was sampled. The research primarily used quantitative methods (85\%) and cross-sectional designs (67\%). Parent- or self-report questionnaires were the most common methods for assessing coping (86\%). Of the 95 studies that utilized one of the 14 questionnaires with known psychometric properties, 33.7 and 55.8\% had one or more discrepancies for conceptual and measurement consistency, respectively.

Conclusions: This review highlights the lack of clear descriptions and theoretical frameworks of coping responses for pediatric chronic pain. Inconsistencies in the measurement and conceptualization of coping responses limit research and clinical 
advancements. As a field, we need to strive toward using well-developed theory to create fewer, more well-established standardized measures with clearly defined coping responses. Opportunities for qualitative and observational research in more diverse patient populations should be considered for theory construction and measure validation.

Clinical Trial Registration: https://osf.io/xvn2a/?view_only=eff04e0c0b9649be89d4 03b10e9ff082.

Keywords: coping, coping responses, pediatric chronic pain, scoping review, conceptualization and measurement

\section{INTRODUCTION}

Pediatric chronic pain refers to persistent or recurrent pain in infants, children, and adolescents (herein "youth") that lasts for more than 3 months and lacks an adaptive purpose (Treede et al., 2015). Given the long-lasting and unpredictable nature of chronic pain, youth rely on coping to manage their pain and its impact (Peres and Lucchetti, 2010). Coping is defined as the use of intentional and effortful thoughts or behaviors to manage the internal and external demands of stressful situations or experiences (Compas et al., 2014). Rudolph et al. (1995) proposed a model that conceptualizes coping to occur in a sequence of events (i.e., a "coping episode") consisting of coping responses, goals, and outcomes. Within this model, coping responses are defined as mental or physical actions initiated in relation to a perceived stressor (Rudolph et al., 1995). Coping goals are the reasons for engaging in a particular coping response, and coping outcomes are the specific consequences of a coping response. Coping responses may serve different goals and be related to different outcomes across time and situations (Skinner et al., 2003). Therefore, our ability to understand the efficacy and implementation of a coping episode depends on successfully identifying and measuring coping responses. Although there are other models of coping (Skinner et al., 2003; Stanisławski, 2019), this review uses the abovementioned terminology to summarize the literature.

The coping literature is vast, heterogenous, and difficult to interpret. In an effort to better understand this literature, reviews have summarized and critically evaluated the measurement and conceptualization of coping in adult chronic pain (Peres and Lucchetti, 2010), childhood chronic illness (Rudolph et al., 1995; Compas et al., 2012), and general stress (Jensen et al., 1991; Skinner et al., 2003; Garcia, 2010; Stanisławski, 2019); however, there is no review of coping in pediatric chronic pain. This is a critical gap considering that coping responses may vary by health condition as well as age (Garcia, 2010; Compas et al., 2012). For example, chronic pain is often perceived as less predictable and controllable than other chronic illnesses (Compas et al., 2012). Consequently, youth with chronic pain may rely more on coping responses aimed at adapting to their pain such as "distraction" or "acceptance" rather than efforts to change their pain or emotional response to the pain (e.g., "problem-solving", "emotional regulation"). Moreover, developmental changes in perceived control and competence, in combination with sociocultural factors (e.g., culture and gender), influence the way people choose and implement various coping responses (Compas et al., 1991; Compas, 1998). For instance, children and young adolescents may be less capable of managing their emotional reactions to their pain and depend more directly on their caregivers to cope than older adolescents and adults (Skinner and Zimmer-Gembeck, 2016). Therefore, a comprehensive review of the existing literature on coping in the context of pediatric chronic pain is needed to identify and evaluate measures and conceptualizations of coping responses specific to this population.

In the broader coping literature, several important gaps limit the ability to communicate effectively about coping and consolidate research on effectiveness. With regard to conceptual gaps, there is a lack of consensus about how best to classify and define coping responses (Skinner et al., 2003; Stanisławski, 2019). As such, coping has been conceptualized using over 400 coping responses organized within more than 100 different typologies (Skinner et al., 2003). Typologies of coping are generally hierarchical and multidimensional organization systems where specific coping responses are unidimensional lower-order categories nested within more complex and abstract higher-order categories of coping. Correspondingly, the most widely used conceptualizations of lower- and higherorder coping responses in the pediatric coping literature include coping strategies (i.e., specific and discrete cognitive, emotional, and/or behavioral responses, such as "planning" or "distraction") and coping styles (i.e., a set of coping strategies that fulfill a specific function showing relative stability over time and situations, such as "problem-focused" or "emotionfocused" coping), respectively (Stanisławski, 2019). The extent to which other terminologies have been used remains unclear. Furthermore, the organization of lower-order into higherorder categories is typically accomplished according to their intended function (i.e., the coping goal) and topological distinction (i.e., descriptive categories that are concerned with how children cope) (Skinner et al., 2003). However, given that some lower-order coping responses include multiple functions and behaviors, the use of a classification system may contribute to inconsistencies across coping measures. For example, within "problem-focused" coping (i.e., responses aimed at modifying or eliminating the stressor) and "emotion-focused" coping (i.e., responses aimed at managing the emotions aroused by the stressor), the response of "planning" (identified as a lower-order category on scales assessing coping) can be functional for both "problem-focused" and "emotion-focused" coping by guiding problem-solving and calming negative emotions, respectively. Although theories and definitions can guide more consistent 
conceptualizations of coping responses, they are seldom used (Garcia, 2010). Addressing conceptual inconsistencies (i.e., varied terminologies/categorizations) and ambiguities is critical as they limit our ability to draw conclusions from research and make real-world applications.

Existing reviews also highlight the limitations of having too many measures of coping. Within the general pediatric coping literature, at least 52 measures of a child coping have been identified (i.e., 38 self-report measures, eight observational measures, and six caregiver-report measures) (Blount et al., 2008). The existence of a large number of measures that vary in content and structure contributes to an excessive number of coping responses and makes it difficult to compare and consolidate research findings across studies. In addition, the lack of clear theories and descriptions of coping responses makes it difficult to understand the similarities and differences across measures.

The timing in which coping is assessed in relation to the identified stressor is also not well-understood. Within pediatric chronic pain, proactive coping would include efforts or goals undertaken in advance of a painful episode to prevent it or reduce its severity (e.g., practicing daily mindfulness), and reactive coping would include responses to experiencing pain (e.g., listening to music to distract from pain). Distinguishing between proactive and reactive coping is particularly important for intervention planning. For instance, assessments of proactive coping may be more relevant to interventions aimed at facilitating lifestyle changes. In contrast, interventions aimed at helping youth learn how to cope in response to pain may require assessments of what coping responses are used during painful situations (Ho, 2019). The extent to which studies have appropriately considered the timing of coping in response to pain in the selection and interpretation of coping measures has not yet been examined.

In sum, our ability to perform research and effectively communicate about how youth cope with pain is limited by: (i) the vastness of the literature; (ii) the use of unclear and inconsistent terminologies and categorizations of coping responses; and (iii) inconsistencies in how coping responses are measured across studies. Figure 1 illustrates content, organizational, and definitional challenges by comparing the subscales of the pain response inventory (PRI) (Walker et al., 1997 ) and the pain coping inventory (PCQ) (Reid et al., 1998), the two most frequently cited (Web of Science citation count: PRI $=197$ articles and PCQ $=164$ ) and well-established measures of pain-related coping in youth (Blount et al., 2008). The extent to which these challenges apply in the field of pediatric chronic pain remains unclear. Thus, a scoping review was conducted to systematically map the measurement and conceptualization of coping in populations with pediatric chronic pain. Specific research questions were as follows:

1) In whom, what, why, and how are coping responses measured? Specific characteristics of interest were: (i) The "who"the sample characteristics (i.e., gender, age, ethnicity, and pain conditions) and study characteristics (i.e., country, year); (ii) the "what" - research methodologies employed (i.e., study design, type of data); (iii) the "why"-applications of theoretical frameworks by study authors; and (iv) the "how"-types of coping measures used and their characteristics (i.e., the name of the measure, purpose, response options, internal reliability of subscales, assessment of proactive vs. reactive coping, parent or youth report, the types of coping responses captured by the subscales, and coping structure used).

2) How have coping responses been conceptualized in the literature? This was examined based on: (i) the operationalized definitions and/or descriptions of coping responses used; (ii) the clarity with which authors defined or described the coping responses measured; (iii) the terminology used to classify coping responses within higherand lower-order categories (e.g., coping strategies vs. coping styles); and (iv) the extent to which the selection of coping measures was grounded in a clear theoretical or empirical rationale (herein "concept guided").

3) Are coping responses measured and conceptualized consistently relative to their intended purpose? This review evaluated the extent to which: (i) the appropriate validation studies were cited; (ii) measures were used consistently (i.e., measurement consistency); and (iii) concepts were described consistently with what the original scale purports to measure (i.e., conceptual consistency).

\section{METHODS}

This scoping review was developed using the methodological framework put forward by Arksey and O’Malley (2005) and further refined by the Joanna Briggs Institute (Peters et al., 2019) and was written in accordance with the PRISMA-ScR reporting guidelines (Tricco et al., 2018). A scoping review approach allows for a descriptive account of the available information in a particular field and is ideal for broadly defined research questions and heterogeneous sources of evidence, which can then guide future narrower systematic reviews (Sucharew, 2019). The literature reviewed was derived from a larger review of positive psychological factors in the context of pediatric chronic/recurrent pain (see Supplementary Materials); only peer-reviewed articles pertaining to youth pain-related coping were included in this study. The study protocol and materials are available via Open Science Framework (https://osf.io/xvn2a/? view_only=eff04e0c0b9649be89d403b10e9ff082).

\section{Eligibility Criteria \\ Population}

Studies that examined a pediatric population (youth $0-18$ years of age). Studies with participants above the age of 18 were retained only if they included a pediatric sample that extended into young adulthood with a maximum age of 21 (Hardin and Hackell, 2017). Studies that examined adult, both pediatric and adult (above 21 years of age), and/or animal populations were excluded.

\section{Concept}

The main concept of interest is youth pain-related coping, which includes the use of coping responses by youth to manage pain 


\section{Pain Response Inventory (PRI)}

\section{Pain Coping Questionnaire (PCQ)}

\section{Accommodative coping (Responses that enable the individual to adapt to unchangeable stressful conditions.) \\ Minimizing Pain (no definition provided) \\ - Tell yourself that its not that bad. \\ Self-encouragement (no definition provided) \\ - Tell yourself you can get over your pain. \\ Acceptance (no definition provided) \\ - Tell yourself "That's life". \\ Distract/Ignore (no definition provided) \\ - Do something you enjoy so you won't think about it. (see PCQ Behavioral Distraction) \\ - Try not to think about it. (see PCQ Cognitive Distraction)}

Stoicism (Inhibiting or minimizing the expression of one's pain or distress to others.)

- Keep others from knowing how much it hurts.

Passive coping (no definition provided)

Catastrophizing (no definition provided)

- Think to yourself that it's never going to stop.

Behavioural Disengagement (no definition provided)

- Give up trying to feel better.

Self-isolation (no definition provided)

- Go off by yourself.

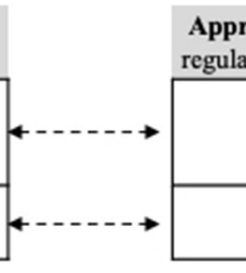

Approach coping (Direct attempts to deal with the pain and regulate feelings when in the pain.)

Problem Solving (no definition provided)

- Think about what needs to be done to make things better.

Seeking Social Support (no definition provided)

- $\quad$ Talk to someone about how I am feeling.

Information Seeking (no definition provided)

- Ask questions about the problem.

Positive Self-statements (no definition provided)

- Tell myself its not so bad. (see PRI Minimizing Pain)

- Tell myself things will be okay. (see PRI Selfencouragement)

FIGURE 1 | Using the PRI (Walker et al., 1997) and the PCQ (Reid et al., 1998), this figure illustrates the inconsistencies in content (e.g., items, subscales) and organization (categorizations of coping responses) as well as the use of definitions across measures. The gray boxes indicate the higher-order factors, and the lined boxes indicate subscales that appear conceptually similar across measures. Example items are provided in italics. Dotted lines connect subscales that appear to be similar on each measure and demonstrate differences in their categorization within higher-order categories. Of note, the PRI and PCQ assess three different higher-order factors. Some lower-order coping responses either sound the same (e.g., "problem-solving") or consist of similar items (e.g., "positive self-statements", "minimizing pain", and "self-encouragement"), but the extent to which these seemingly similar subscales should be conceptualized the same way is unclear due to the lack of clear definitions and inconsistent categorizations within higher-order factors [i.e., "problem solving" as "active coping" (PRI) vs. "approach coping" (PCQ); "seeking social support" as "active coping" (PRI) vs. "approach coping" (PCQ); "catastrophizing" as "passive coping" (PRI) vs. "emotion-focused avoidance" (PCQ); "positive self-statements" (conceptually similar to "self-encouragement" and "minimizing pain" combined) as "accommodative coping" (PRI) vs. "approach coping" (PCQ); and "distract/ignore" (conceptually similar to "cognitive distraction" and "behavioral distraction" combined) as "accommodative coping" (PRI) vs. "problem-focused avoidance" (PCQ)].

or pain-related stressors. Pain catastrophizing in the context of coping (i.e., the tendency to magnify the threat associated with pain and to forecast negative outcomes) (Quartana et al., 2009) was excluded because it has been well-documented as a non-adaptive cognitive-affective response to chronic pain that has been reviewed on its own (Vervoort et al., 2006; Leung, 2012). The exclusion of catastrophizing is also consistent with previous reviews, which have conceptualized catastrophizing as a unique psychological factor rather than a type of coping response (Sharma et al., 2020).

\section{Context}

Studies including youth with chronic pain conditions (i.e., persistent and/or recurrent pain) were included. Examples 
of included pediatric chronic pain conditions are sickle cell disease, juvenile arthritis, complex regional pain syndrome, and abdominal pain, among others. In line with other pediatric chronic pain reviews (Lewandowski et al., 2010; King et al., 2011; Eccleston et al., 2014), studies that exclusively examined a diverse pediatric chronic illness group (e.g., non-chronic pain disorders such as diabetes and asthma) or cancer-related pain were excluded. Finally, studies that examined "recurrent pain" in healthy samples drawn from community or school samples of children were excluded.

\section{Types of Evidence Sources}

English language articles containing original data published in scientific journals were included. All non-peer-reviewed publications (e.g., dissertations), reviews, commentaries, editorials, and chapters were excluded. Non-English language studies were excluded due to feasibility (i.e., the lack of translators on the research team).

\section{Stage One: Database Searches and Screenings}

Electronic literature searches were conducted by a lead researcher (RMT or ANN) in MEDLINE (PubMed) and PsycINFO in three phases between March 26, 2015 and August 20, 2020. Databases were selected in accordance with Cochrane Review recommendations for reviews in the fields of medicine and psychology (Higgins and Green, 2008). All citations were uploaded into EndNote, and the titles and abstracts were screened for inclusion prior to conducting full-text screenings and extractions. Upon completion of a training period (i.e., 100 articles), title/abstract screenings were completed by two reviewers within EndNote, including undergraduate research assistants and/or a lead researcher (RMT or ANN), and interrater reliability was calculated based on percentage agreements.

The first two phases (March 26, 2015; September 4, 2018) employed double coding for $20 \%$ of all articles identified and had inter-rater reliability of $89 \%$ at the abstract level. In the third phase (August 20, 2020), all title/abstract screenings were double-coded and had an inter-rater agreement of $98.3 \%$. Articles were then screened at the full-text level by two reviewers. All included articles were checked by the lead researcher (ANN) prior to inclusion, and any discrepancies were resolved through discussion.

\section{Stage Two: Data Extraction}

Information was extracted on study details (e.g., the year of study, country), participant characteristics (e.g., gender, age), and methodological characteristics (e.g., study designs, types of data collected). In addition, characteristics of the measures used (e.g., number of items, the content/structure, timing of coping assessed) and the terminologies and conceptualizations of the coping responses assessed (e.g., theoretical frameworks, definitions/descriptions, categorization of coping types) were extracted from the included studies. The appropriateness of the measure selected in each included study of the review was evaluated based on whether the concepts assessed were in alignment with the stated research objectives/hypotheses and/or theoretical framework of the authors (i.e., a concept-guided approach), which is a recommended approach for developing and validating knowledge (Coster, 2013; Boateng et al., 2018). In order to map the current published research literature, study authors were not contacted for missing information.

A standardized data extraction form was piloted on a random sample of 10 included articles and modified as required based on feedback from other reviewers. A final revision and the pilot of the extraction spreadsheet were completed on July 10, 2020. All extractions were completed by the primary researcher (ANN) and were reviewed and verified by a second reviewer (an undergraduate research assistant). The number of disagreements between reviewers per article ranged from 0 to 4 out of 45 decisions made per article $(M d n=1.00, M=0.99, S D=1.08)$ and was resolved through discussion between the two reviewers or adjudication by a third researcher (CMM) as needed. The following subsections will outline key areas of consideration and procedures used in the data extraction process.

\section{Stage Three: Comparisons With Original Scale Development Studies}

Scale development/validation studies were identified from the database search $(n=4)$ as well as via snowball searching (i.e., using the included studies as a starting point and pursuing references for assessment tools cited by the study authors; $n=20$ ). Appropriateness of the measure selected, as well as the accuracy and clarity of the use of the coping measures and concepts, was determined by examining information from the scale development studies. An "overview document" (see Supplementary Materials for a sample) of the scale development studies was developed for each measure that included information on the participant characteristics, theoretical background, measure characteristics, and definitions of coping responses. Each overview document was checked by a lead researcher (ANN) prior to being used.

For studies that used a questionnaire with published information on its psychometric properties, comparisons between each included study and the respective scale development study/studies were completed to determine measurement consistency, conceptual consistency, and conceptual clarity (see Table $\mathbf{1}$ for more information). For conceptual clarity and consistency, the use of both definitions (i.e., a statement that describes the meaning of a concept) and examples (i.e., describing a specific behavior or naming subtypes of coping responses) were evaluated because they are both important elements of a well-established concept (Gerring, 1999) and have been used to explain coping in previous research (Garcia, 2010). The rating scales employed were adapted from recommendations by the Cochrane Review Groups to maximize the simplicity and clarity of the coding schemes (Lundh and Gøtzsche, 2008). These rating scales are not an assessment of methodological quality but rather highlight when our ability to directly interpret, consolidate, and/or compare research findings may be limited. All three rating scales were evaluated by two reviewers (an undergraduate research assistant and ANN), and agreement was assessed using percent agreement. 
TABLE 1 | Operationalization of measurement consistency, conceptual consistency, and conceptual clarity (adapted from the Cochrane Review Groups recommendations) (Lundh and Gøtzsche, 2008).

\begin{tabular}{|c|c|c|}
\hline Domain & Description & ${ }^{\text {a }}$ Ratings \\
\hline $\begin{array}{l}\text { Measurement } \\
\text { consistency }\end{array}$ & $\begin{array}{l}\text { The extent to which the author } \\
\text { appropriately used the measure } \\
\text { selected. }\end{array}$ & $\begin{array}{l}\text { High: The use of the coping measure employed was fully consistent with the scale development study. } \\
\text { Low: There is at least one discrepancy in how the coping measure was used relative to the scale development } \\
\text { study. } \\
\text { Unclear: Unable to evaluate measurement consistency due to insufficient information (e.g., missing more than } \\
\text { two relevant characteristics) }\end{array}$ \\
\hline $\begin{array}{l}\text { Conceptual } \\
\text { consistency }\end{array}$ & $\begin{array}{l}\text { The extent to which the } \\
\text { b descriptors of coping used in a } \\
\text { particular study are consistent } \\
\text { with the descriptors that were } \\
\text { proposed by the scale } \\
\text { development study. }\end{array}$ & $\begin{array}{l}\text { High: The descriptors of all coping constructs were fully consistent with the scale development study. } \\
\text { Low: There is at least one discrepancy in how coping was described between the study and scale } \\
\text { development study. } \\
\text { Unclear: Unable to evaluate conceptual consistency due to insufficient information (e.g., there are no } \\
\text { descriptors of the coping constructs in the study or the corresponding scale development study). }\end{array}$ \\
\hline Conceptual clarity & $\begin{array}{l}\text { The extent to which coping } \\
\text { constructs were defined or } \\
\text { described using examples. }\end{array}$ & $\begin{array}{l}\text { High: All relevant coping terms were clearly defined AND potential applications of the coping construct were } \\
\text { provided. } \\
\text { Moderate: All relevant coping terms were either clearly defined OR potential applications of the coping } \\
\text { construct were provided. } \\
\text { Low: Some relevant coping terms were defined and/or potential applications were provided. } \\
\text { Very Low: No relevant coping terms were defined, and no potential applications were provided. }\end{array}$ \\
\hline
\end{tabular}

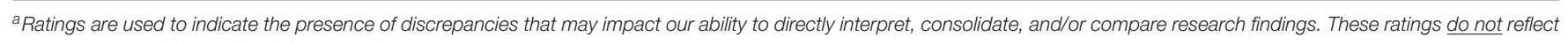
an assessment of the quality of the research.

${ }^{b}$ Descriptors $=$ refer to the use of definitions and/or examples.

High agreement was found between reviewers for ratings of conceptual clarity $(91.2 \%)$, measurement consistency $(88.4 \%)$, and conceptual consistency (89.5\%).

\section{Data Synthesis}

The results were summarized using a combination of descriptive numerical and narrative summaries in accordance with the research questions. All numerical descriptive statistics (means and proportions) were conducted using SPSS version 26. Weighted means were used to summarize participant characteristics (i.e., age and gender) to account for sample size differences.

\section{RESULTS}

As shown in Figure 2, database searching identified 37,172 potential articles encompassing a wider range of positive psychological factors associated with adjustment in youth with chronic pain. After the removal of duplicates and articles that did not meet the inclusion criteria for this review at the title/abstract level of screening, 1,159 articles remained. Of these articles, 129 articles met the eligibility criteria for full-text review. Scale development/validation studies identified from the database search $(n=4)$ were reviewed separately and used as a reference to evaluate the measurement and conceptual consistency of research studies in the field. Thus, 125 peer-reviewed articles related to coping and pediatric chronic pain were included in this review (see Supplementary Table 1 for a list of included studies) (Moher et al., 2009).

\section{Aim 1: The Who, What, Why, and How of Measuring Pain-Related Coping in Youth}

Table 2 provides an overview of the included studies; see Supplementary Table 2 for the participant, study, and methodological characteristics of each individual study. Studies were published between 1991 and 2020. The vast majority of studies $(88 \%)$ were conducted in the USA $(n=84 ; 67.2 \%)$ and countries in Western Europe $(n=26 ; 20.8 \%)$.

\section{Who: Sample Characteristics}

The articles included 13,474 youth who were predominately female (weighted mean $=65 \%$, weighted SD $=0.12 \%$ ). The participants ranged from 3 to 20 years old (weighted mean $=12.8$ years, weighted $S D=2.25$ ).

The participants presented with a wide range of pain conditions (Table 2), with the most frequent being sickle cell disease (SCD; 33.6\%) and abdominal pain (16.0\%). A heterogenous chronic pain sample was used in $21.6 \%$ of studies. Only 78 studies (62.4\%) reported on the ethnic and/or racial composition of the participants. When reported, the participants were predominately White $(n=41 ; 54.5 \%)$. The only exception was studies on sickle cell disease, wherein the majority of the participants were African American or Black $(n=32 ; 41.0 \%$ of studies that reported on ethnicity/race).

\section{What: Study Design and Data Collection Method}

The majority of included studies examined youth pain-related coping using a cross-sectional $(n=85 ; 67.2 \%)$ approach. Of the studies that measured coping as an outcome of a cognitive, behavioral, or physical intervention for youth with chronic pain $(n=34), 51.5 \%(n=17)$ had a control or comparison group. Additional 16 studies used a control or comparison group without examining the effects of an intervention.

\section{Why: Theoretical Frameworks}

Just over a third of included studies identified a theoretical conceptualization of coping $(n=45 ; 36 . \%)$. Of these 45 studies, the majority $(n=29)$ referred to theoretical frameworks of 


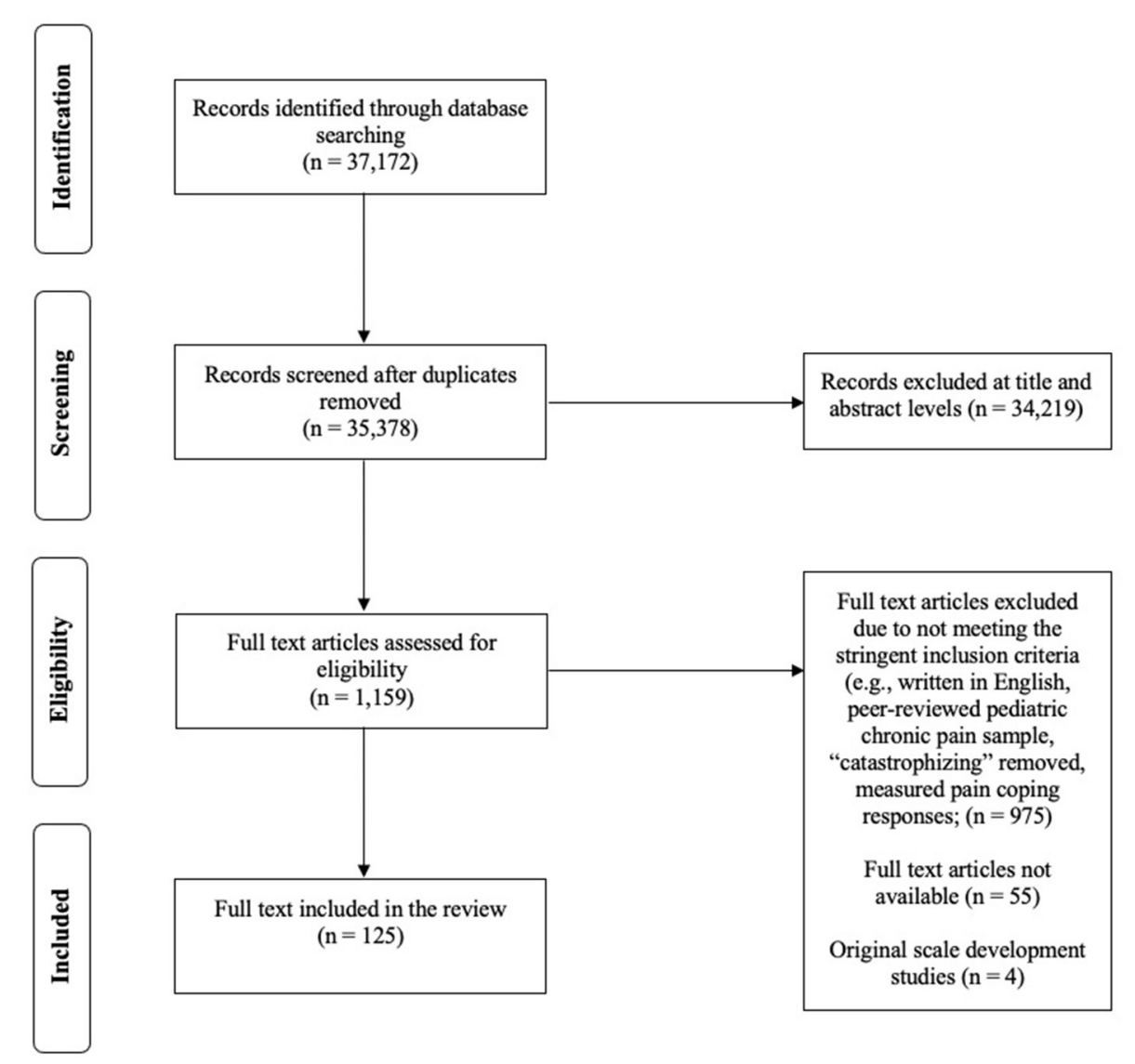

FIGURE 2 | Included a study flow chart following PRISMA guidelines.

the coping process (e.g., the biopsychosocial model, riskresistance model, transactional stress, and coping model) as opposed to conceptualizations of specific coping responses. Five theoretical models conceptualizing specific coping responses were identified within 16 included articles. The most common theory cited was the cognitive-appraisal theory of Lazarus and Folkman $(n=8)$, which suggests that coping responses can be categorized as being "problem-focused" (i.e., coping that is aimed at managing or altering the problem causing the distress) or "emotion-focused" (i.e., coping that is directed at regulating emotional responses to the problem) (Lazarus and Folkman, 1984). Following a similar dichotomous structure, the approach- vs. avoidance framework purposed by Roth and Cohen was used in one study, conceptualizing coping responses as cognitive and emotional strategies that are oriented either toward or away from the stressor, respectively (Roth and Cohen, 1986). Alternatively, five studies referred to the control-based model as a more complex, hierarchical classification system that distinguishes between voluntary vs. involuntary (i.e., unconscious vs. intentional/volitional responses) and engagement vs. disengagement processes (i.e., oriented toward or away from the stressor) (Compas et al., 1991). Within the control-based model, coping is characterized as voluntary responses that can be distinguished by engagement vs. disengagement responses. Engagement responses are further distinguished by their goals: "primary-control-engagement" coping involves attempts to alter emotions (e.g., emotion regulation) or the stressor itself (e.g., problem-solving), whereas "secondary-control-engagement" coping includes efforts to become accustomed to the stressor by modifying cognitions or regulating attention (e.g., acceptance). In contrast, "disengagement" coping involves both removing oneself from the stressor and removing oneself from his or her emotions related to the stressor.

As an alternative to the abovementioned hierarchical classifications of coping responses, one study referred to the typology of Walker and colleagues to explain meaningful patterns of coping responses that are used by youth with chronic abdominal pain and their association with different levels of emotional and physical distress (i.e., coping profiles) (Walker et al., 2008). For example, using cluster analytic techniques with the PRI scales, patients identified as "engaged copers" were characterized by using high levels of "distraction" and "social support-seeking" and associations with lower levels of depressive symptoms and disability, representing an overall adaptive pattern of coping responses. As such, coping profiles 
TABLE 2 | Overview of characteristics of the included studies $(N=125)$.

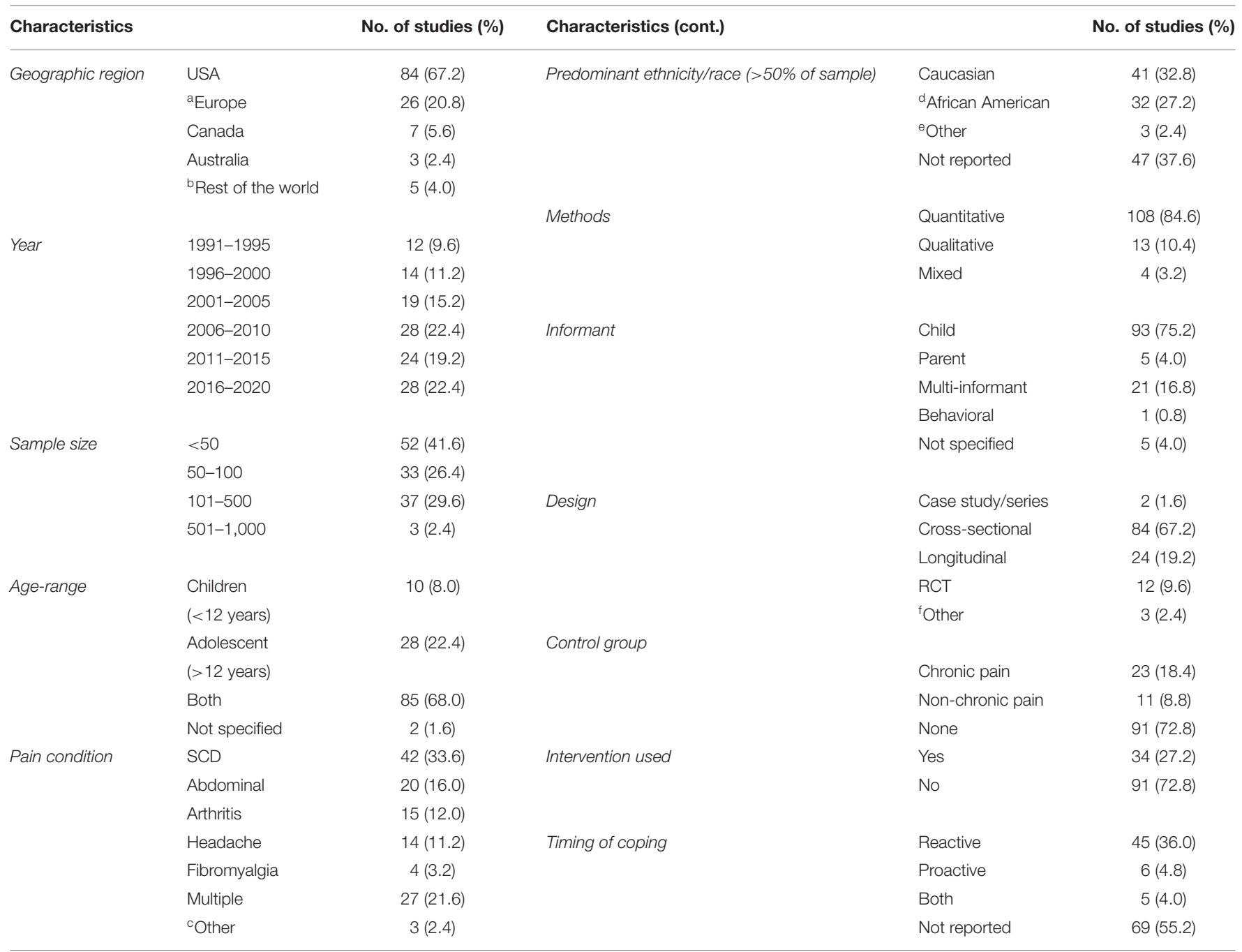

$S C D$, sickle cell disease; $R C T$, randomized control trail.

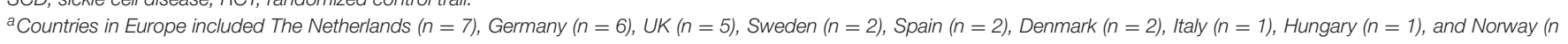
$=1)$.

${ }^{b}$ Other countries included Brazil $(n=2)$, India $(n=1)$, Jamaica $(n=1)$, and Lebanon $(n=1)$.

${ }^{c}$ Other pain conditions include complex regional pain syndrome ( $\left.n=1 ; 0.8\right)$, non-cardiac chest pain $(n=1 ; 0.8)$, and systemic lupus erythematosus ( $\left.n=1 ; 0.8\right)$.

${ }^{d}$ All 32 studies that focused predominantly on an African American sample were concerned with a diagnosis of sickle cell disease.

${ }^{e}$ Other predominant ethnic/racial groups include Hispanic $(n=1)$, East Indian $(n=1)$, and Lebanese/Palestinian $(n=1)$.

${ }^{f}$ Other designs include non-RCT pre-post design $(n=1)$, retrospective chart review $(n=1)$, and ethnography $(n=1)$.

were conceptualized to retain information about the specific coping responses while capturing the relationship between coping responses and outcomes.

\section{How: Types of Measures}

The vast majority of studies employed only quantitative measures ( $n=108 ; 86.4 \%$; see Table 2$)$, primarily questionnaires $(n=$ 105; see Table 3). Other questionnaires that did not have a peerreviewed and/or English development/validation study include: the child and adolescent coping inventory $(n=1)$ (Harris et al., 1991); sick-role adoption index $(n=1)$ (Barbarin et al., 1999); Utrecht coping list $(n=1)$ (Westendorp et al., 2017); stress and coping questionnaire for children and adolescents $(n=1)$ and other coping scales derived by the authors of the included study $(n=3)$.

Other quantitative measures included structured daily diaries $(n=6)$, structured interviews using closed-end questions $(n=2)$, observations of child behavior $(n=1)$, or an unspecified measure $(n=1)$. Of the quantitative studies, five studies $(4.6 \%)$ reported using multiple quantitative measures (e.g., a questionnaire and the daily pain and activity diary). Qualitative measures for assessing coping responses included semi-structured interviews with open-ended questions $(n=9)$, unstructured interviews $(n=$ $2)$, drawings $(n=1)$, written narrative tasks $(n=1)$, and clinician judgements based on a retrospective chart review of clinical notes and patient interactions $(n=1)$. 
TABLE 3 | A list of the questionnaires identified with clear development studies available, reporting psychometrics, ordered by most to least frequently used measure.

\begin{tabular}{|c|c|c|c|c|c|c|}
\hline Measure/No. of items & $\begin{array}{l}\text { Population } \\
\text { (P)/Informant (I) }\end{array}$ & Timing & $\begin{array}{l}\text { Subscales/Factors (Cronbach's alpha, if } \\
\text { provided) }\end{array}$ & $\begin{array}{l}\text { Response } \\
\text { options/Scoring }\end{array}$ & $\begin{array}{l}\text { aNo. of } \\
\text { studies }\end{array}$ & $\begin{array}{l}{ }^{\text {b Citation }} \\
\text { accuracy } \\
(\%)\end{array}$ \\
\hline $\begin{array}{l}\text { Pain Response Inventory } \\
\text { (PRI); } 60 \text { items (Walker } \\
\text { et al., 1997) }\end{array}$ & $\begin{array}{l}\text { P: School-aged } \\
\text { sample and youth } \\
\text { with recurrent } \\
\text { abdominal pain; } \\
\text { ages ranged from } 8 \\
\text { to } 23 \\
\text { I: Youth form }\end{array}$ & Reactive & $\begin{array}{l}\text { Active coping } \\
\text { Problem solving } \\
\text { Seeking social support } \\
\text { Rest } \\
\text { Massage/Guard } \\
\text { Condition-specific strategies } \\
\text { Passive coping } \\
\text { Behavior disengagement } \\
\text { Self-isolation } \\
\text { Catastrophizing } \\
\text { Accommodative coping } \\
\text { Acceptance } \\
\text { Minimizing pain } \\
\text { Distract/lgnoring pain } \\
\text { Stoicism }\end{array}$ & $\begin{array}{l}\text { Five-point scale } \\
\text { (Never to Always)/Factor } \\
\text { and subscale scores are } \\
\text { derived by computing the } \\
\text { means across items or } \\
\text { subscales, respectively. }\end{array}$ & 19 & 100 \\
\hline $\begin{array}{l}\text { Pediatric Pain Coping } \\
\text { Inventory (PPCI) } 41 \text { items } \\
\text { (Varni et al., 1996) } \\
\text { Alternate version: } \\
\text { PPCl-Revised (German) } \\
\text { (Hechler et al., 2008) }\end{array}$ & $\begin{array}{l}\text { P: Children and } \\
\text { adolescents with } \\
\text { musculoskeletal } \\
\text { pain, ages 5-16 } \\
\text { I: Child, adolescent } \\
\text { and parent forms }\end{array}$ & Reactive & $\begin{array}{l}\text { Cognitive self-instruction }(0.77) \\
\text { Seek social support }(0.74) \\
\text { Strive to rest and be alone }(0.73) \\
\text { Cognitive refocusing }(0.68) \\
\text { Problem-solving self-efficacy }(0.67)\end{array}$ & $\begin{array}{l}\text { Three-point scale } \\
(0=\text { Not at all, } 3= \\
\text { Often)/Subscale scores are } \\
\text { derived by computing the } \\
\text { means across items. }\end{array}$ & 7 & 100 \\
\hline $\begin{array}{l}\text { KidCope } \\
\text { Adolescent version; } 10 \\
\text { items (Spirito et al., 1988) } \\
\text { Child version; } 15 \text { items } \\
\text { (Spirito et al., 1991) }\end{array}$ & $\begin{array}{l}\text { Adolescent: } \\
\text { P: High school } \\
\text { sample and chronic } \\
\text { pain patients, ages } \\
\text { 12-18 } \\
\text { Child: } \\
\text { P: Children, ages } \\
\text { 9-13 } \\
\text { I: Youth }\end{array}$ & Reactive & $\begin{array}{l}\text { Problem-solving } \\
\text { Distraction } \\
\text { Social support } \\
\text { Social withdrawal } \\
\text { Cognitive restructuring } \\
\text { Self-criticism } \\
\text { Blaming others } \\
\text { Emotional regulation } \\
\text { Wishful thinking } \\
\text { Resignation }\end{array}$ & $\begin{array}{l}\text { Adolescent: } \\
\text { Four-point scale } \\
\text { (Not at all to Almost all the } \\
\text { time) } \\
\text { Child: } \\
\text { Yes or no } \\
\text { Scoring was not specified }\end{array}$ & 6 & 16.7 \\
\hline
\end{tabular}


TABLE 3 | Continued

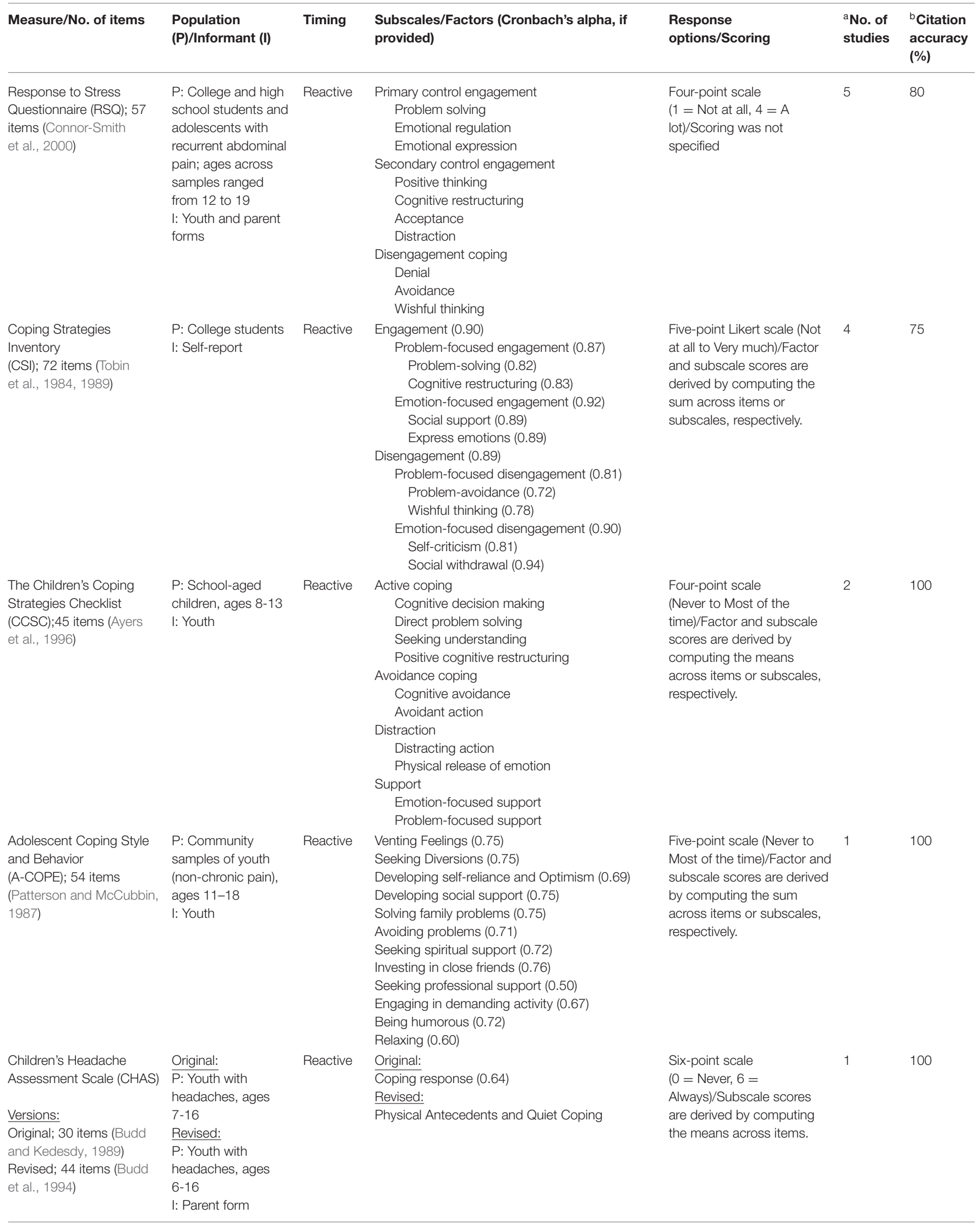


TABLE 3 | Continued

\begin{tabular}{|c|c|c|c|c|c|c|}
\hline Measure/No. of items & $\begin{array}{l}\text { Population } \\
\text { (P)/Informant (I) }\end{array}$ & Timing & $\begin{array}{l}\text { Subscales/Factors (Cronbach's alpha, if } \\
\text { provided) }\end{array}$ & $\begin{array}{l}\text { Response } \\
\text { options/Scoring }\end{array}$ & $\begin{array}{l}\text { aNo. of } \\
\text { studies }\end{array}$ & $\begin{array}{l}{ }^{\mathrm{b}} \text { Citation } \\
\text { accuracy } \\
(\%)\end{array}$ \\
\hline $\begin{array}{l}\text { How I Coped Under } \\
\text { Pressure Scale } \\
\text { (HICUPS); } 45 \text { items (Ayers } \\
\text { et al., 1996) }\end{array}$ & $\begin{array}{l}\text { P: School sample, } \\
\text { ages } 9-13 \\
\text { I: Youth }\end{array}$ & Reactive & $\begin{array}{l}\text { Active coping } \\
\text { Cognitive decision-making }(0.71) \\
\text { Direct problem-solving }(0.71) \\
\text { Seeking understanding }(0.74) \\
\text { Positive cognitive restructuring }(0.62) \\
\text { Avoidance coping } \\
\text { Cognitive avoidance }(0.61) \\
\text { Avoidant action }(0.64) \\
\text { Distraction } \\
\text { Distracting action }(0.65) \\
\text { Physical release of emotion }(0.65) \\
\text { Support } \\
\text { Emotion-focused support }(0.60) \\
\text { Problem-focused support }(0.57)\end{array}$ & $\begin{array}{l}\text { Four-point scale } \\
\text { (Not at all to A lot)/Factor } \\
\text { and subscale scores are } \\
\text { derived by computing the } \\
\text { sum across items or } \\
\text { subscales, respectively. }\end{array}$ & 1 & 100 \\
\hline $\begin{array}{l}\text { The Schoolagers Coping } \\
\text { Strategies Inventory } \\
\text { (SCSI); } 30 \text { items } \\
\text { (Ryan-Wenger, 1990) }\end{array}$ & $\begin{array}{l}\text { P: Community } \\
\text { sample ( } 10 \% \text { with a } \\
\text { chronic health } \\
\text { condition, e.g., } \\
\text { asthma, allergies), } \\
\text { ages } 8-12 \\
\text { I: Youth }\end{array}$ & Reactive & $\begin{array}{l}\text { Social support } \\
\text { Avoidant } \\
\text { Emotional } \\
\text { Distracting } \\
\text { Cognitive } \\
\text { Aggressive motor } \\
\text { Physical exercise } \\
\text { Isolating } \\
\text { Aggressive verbal Relaxation } \\
\text { Habitual } \\
\text { Spiritual } \\
\text { Other }\end{array}$ & $\begin{array}{l}\text { Three-point scale } \\
\text { (frequency)/Scoring was not } \\
\text { specified }\end{array}$ & 1 & 100 \\
\hline $\begin{array}{l}\text { Ways of Coping Checklist; } \\
64 \text { items (Folkman and } \\
\text { Lazarus, 1980) }\end{array}$ & $\begin{array}{l}\text { P: Adults, ages } \\
45-64 \\
\text { I: Self-report }\end{array}$ & Unclear & $\begin{array}{l}\text { Problem-focused coping }(0.80) \\
\text { Emotion focused coping }(0.81)\end{array}$ & $\begin{array}{l}\text { Yes or No/Scoring was not } \\
\text { specified }\end{array}$ & 1 & 100 \\
\hline $\begin{array}{l}\text { Religious Coping } \\
\text { (R-COPE); } 105 \text { items } \\
\text { (Pargament et al., 2000) }\end{array}$ & $\begin{array}{l}\text { P: College } \\
\text { sample who } \\
\text { encountered a } \\
\text { negative life event, } \\
\text { ages 18-38; } \\
\text { hospitalized adults } \\
\text { with a moderately } \\
\text { severe medical } \\
\text { illness, ages 55-97 } \\
\text { I: Self-report }\end{array}$ & $\begin{array}{l}\text { Not } \\
\text { reported }\end{array}$ & $\begin{array}{l}\text { Benevolent religious reappraisal }(0.91) \\
\text { Punishing God reappraisal }(0.92) \\
\text { Demonic reappraisal }(0.90) \\
\text { Reappraisal of God's power }(0.78) \\
\text { Collaborative religious coping }(0.89) \\
\text { Active religious surrender }(0.92) \\
\text { Passive religious deferral }(0.83) \\
\text { Pleading for direct intercession }(0.84) \\
\text { Religious focus }(0.84) \\
\text { Purification/forgiveness }(0.93) \\
\text { Spiritual connection }(0.81) \\
\text { Spiritual discontent }(0.88) \\
\text { Marking religious boundaries }(0.61) \\
\text { Seeking support from clergy }(0.90) \\
\text { Religious helping (0.90) } \\
\text { Interpersonal religious discontent }(0.82) \\
\text { Religious direction/conversion }(0.94)\end{array}$ & $\begin{array}{l}\text { Four-point scale } \\
\text { (Not at all to A great } \\
\text { deal)/Subscale scores are } \\
\text { derived by computing the } \\
\text { means across items. }\end{array}$ & 1 & 100 \\
\hline
\end{tabular}

The scale characteristics and reliability estimates provided are based on the original scale development study.

${ }^{a}$ A list of each individual study and the study characteristics can be found in Supplementary Table 2.

${ }^{b}$ Citation accuracy refers to the extent to which authors of the included studies cited the correct scale development study.

Overall, $75.2 \%$ of included studies indicated using child selfreport $(n=93)$, and the remaining studies (16.8\%) used multiple informants $(n=20$ child and parent; $n=1$ child, parent, siblings, and clinicians), parent-reported responses $(n=5 ; 4 \%)$, behavioral data $(n=1 ; 0.8 \%)$, or did not specify $(n=5 ; 4 \%)$. Of the 56 studies that explicitly specified the timing of the coping responses assessed in relation to pain, $80.3 \%$ indicated measuring reactive coping responses $(n=45)$ and with the remainder reporting on proactive coping $(n=6)$ or both $(n=5)$. Current measures/approaches used to assess proactive coping consisted open-ended interviews $(n=5)$ and daily diary tools $(n=6$; see Supplementary Table 3). 


\section{Aim 2: Conceptualizations of Coping Responses}

A total of 168 coping responses were identified across all included studies (see Supplementary Table 4 for a full list). The following sections summarize: (i) the terminology used for classifying coping responses; (ii) the extent to which coping responses were clearly defined and/or described (conceptual clarity); and (iii) the extent to which authors used a concept-guided approach to measurement selection.

\section{Terminology for Classifying Coping Responses}

Across the 125 included studies, $21.6 \%(n=27)$ reported on only "coping strategies". Of these studies, the term "coping strategies" was occasionally interchanged with "coping behaviors" or "coping skills". Furthermore, 38.4\% $(n=48 / 125)$ of the included studies reported on higher-order categories of coping only, of which $75 \%(n=36 / 48)$ did not provide a label for the higher-order categorization. Only seven of these 48 studies (14.5\%) explicitly referred to the higher-order categories as "coping styles". In addition, the term "coping style" was used interchangeably with the following terms: "coping patterns", "coping approaches", "dimensions of coping", "coping subtypes" "coping subthemes", "domains of coping", "coping potential”, or "coping response". In addition, 6.4\% $(n=8 / 125)$ of included studies used a term other than coping strategy or style to categorize coping responses (e.g., coping mechanism, coping behavior, coping skill) and $17.6 \%(n=22 / 125)$ reported on multiple levels of coping responses (e.g., coping strategies and coping styles). Sixteen percent of the included studies ( $n=$ 20/125) did not provide a specific term to classify the coping responses assessed.

\section{Conceptual Clarity}

The majority of the 125 studies were rated as "very low" ( $n$ $=40 ; 32.0 \%)$ or "low" ( $n=19 ; 15.2 \%)$ for conceptual clarity. Forty-seven studies $(37.6 \%)$ were rated "moderate" because they provided either a definition or specific examples of coping behaviors for each coping response, but not both. As such, it was less common for studies to demonstrate "high" conceptual clarity by including both examples and a specific statement defining the coping responses used $(n=19 ; 15.2 \%)$.

\section{Measurement Selection}

A concept-guided approach to measurement selection was used in only $33.3 \%$ of included studies $(n=43)$ as demonstrated by providing a clear and consistent rationale for the chosen measurement tool. Of these 43 studies, 20.9\% $(n=9)$ clearly mapped the measurement tool selected to a theoretical framework of coping responses (as described in Aim 2 above). The remaining $79.1 \%$ of studies $(n=34)$ were rated as concept guided on the basis that the measure employed clearly mapped onto the study questions, hypotheses, and/or objectives.

\section{Aim 3: Evaluations of Measurement and Conceptual Consistency (Questionnaires Only)}

The majority of studies $(76.0 \% ; n=95)$ assessed coping responses using questionnaires with known psychometric properties (Table 3). Measurement and conceptual consistency were assessed for studies that used questionnaires with known psychometric properties because of their widespread use and the availability of previous scale development or validation studies for comparison. As such, Table 4 presents the list of coping responses, corresponding descriptors, and empirically derived classifications assessed by questionnaires with known psychometric properties.

\section{Primary, Secondary, and Tertiary Factor Levels}

There were inconsistencies in the terminology used to classify coping responses. For example, higher-order coping responses were referred to by various terms, such as "coping styles", "coping patterns", or "coping approaches" (see Section Terminology for Classifying Coping Responses for other examples). Thus, exploratory and/or confirmatory factor analysis results from the original scale development studies used represent the hierarchical classifications of coping responses. The terms "primary", "secondary", and "tertiary" correspond to first-, second-, and third-order-factor levels (Table 4). Primary coping responses are made up of related items on a questionnaire. Within multidimensional scales, primary coping responses load onto secondary coping responses; and secondary coping responses load onto tertiary coping responses. For example, the PCQ (Reid et al., 1998) consists of eight primary coping responses (problem-solving, information-seeking, seeking social support, positive self-statements, behavioral distraction, cognitive distraction, externalizing, and internalizing) that each loads onto one of the three secondary factors (approach, problem-focused avoidance, and emotion-focused avoidance); Table 3 presents the factor structure of each questionnaire. In summary, there were 86 primary coping responses (e.g., acceptance, cognitive refocusing), 17 secondary coping responses (e.g., active coping, passive coping), and two tertiary coping responses (i.e., engagement, disengagement). Two coping responses were categorized into multiple levels, depending on the measure used (see Table 4): "avoidance" and "disengagement".

\section{Overall Measurement Consistency}

In sum, $55.8 \%(n=53)$ of studies were rated "low", and 23.2\% ( $n=22)$ were rated "high" for measurement consistency. Measurement consistency was rated as "unclear" for $21.1 \%$ of studies $(n=20)$ due to a lack of information about the scale characteristics (i.e., studies that were missing more than two relevant scale characteristics). The most common characteristics missing from articles included the number of items, response options, scoring procedure, and/or the timing of coping strategy use in relation to the pain onset (e.g., proactive vs. reactive).

\section{Overall Conceptual Consistency}

In terms of conceptual consistency, 35.8\% $(n=34)$ of studies were rated "high" (i.e., no discrepancies), and 33.7\% $(n=32)$ of studies were rated "low" (i.e., one or more discrepancies). The remaining $30.5 \%(n=29)$ of studies were rated as "unclear" because the authors did not provide any descriptors to allow for comparison. 
TABLE 4 | A list of coping responses (in alphabetical order) and their corresponding descriptors (if available) conceptualized by questionnaires with a clear scale development study identified (see Table $\mathbf{3}$ for the list of questionnaires).

\begin{tabular}{|c|c|c|c|}
\hline Coping concept & Measure & Descriptor(s) & ${ }^{\mathrm{a}}$ Factor level \\
\hline & RSQ & No definition was provided. Conceptualized as a coping strategy under "secondary control coping". & \\
\hline \multirow[t]{2}{*}{ Active coping } & $\begin{array}{l}\text { CCSC/ } \\
\text { HICUPS }\end{array}$ & $\begin{array}{l}\text { "Strategies in which the child is focused on the stressful event, either to change the situation or to think } \\
\text { about it more positively" (Ayers et al., 1996, p. 929). Includes cognitive decision making, direct } \\
\text { problem-solving, seeking understanding, and positive cognitive restructuring. }\end{array}$ & Secondary \\
\hline & PRI & $\begin{array}{l}\text { No definition was provided. Consists of problem-solving, social support, rest, massage/guard, and } \\
\text { condition-specific strategies. }\end{array}$ & \\
\hline Active religious surrender & RCOPE & "An active giving up of control to God in coping" (Pargament et al., 2000, p. 522) & Primary \\
\hline Aggressive motor & ScSI & No definition was provided. & Primary \\
\hline $\begin{array}{l}\text { Aggressive verbal } \\
\text { relaxation }\end{array}$ & SCSI & No definition was provided. & Primary \\
\hline \multirow[t]{2}{*}{ Avoidance } & $\begin{array}{l}\text { CCSC/ } \\
\text { HICUPS }\end{array}$ & $\begin{array}{l}\text { "Strategies that attempt to manage emotion by trying to avoid or stop thinking about the problem } \\
\text { entirely" (Ayers et al., 1996, p. 930). Includes avoidant actions and cognitive avoidance. }\end{array}$ & $\begin{array}{l}\text { Primary } \\
\text { (RSQ)/ } \\
\text { Secondary } \\
\text { (CCSC/ } \\
\text { HICUPS) }\end{array}$ \\
\hline & RSQ & No definition was provided. Conceptualized as a coping strategy under "disengagement" coping. & \\
\hline \multirow[t]{2}{*}{$\begin{array}{l}\text { Avoidant/Avoidant } \\
\text { actions/Avoiding problems }\end{array}$} & A-COPE & $\begin{array}{l}\text { "Coping behaviors that involve the use of substances (e.g., drinking beer, smoking) as a way to escape } \\
\text { or avoiding persons or issues which cause problems (e.g., staying away from home, telling self the } \\
\text { problem is not important)" (Patterson and McCubbin, 1987, p. 174). }\end{array}$ & Primary \\
\hline & $\begin{array}{l}\text { CCSC/ } \\
\text { HICUPS }\end{array}$ & $\begin{array}{l}\text { "This includes behavioral efforts to avoid the stressful situation by staying away from it or leaving it" } \\
\text { (Ayers et al., 1996, p. 930). Conceptualized as a coping strategy under "avoidance" coping. }\end{array}$ & \\
\hline Blaming others & KIDCOPE & No definition was provided. & Primary \\
\hline Calming self-statements & CSQ-SCD & No definition was provided. Conceptualized as a coping strategy under "coping attempts". & Primary \\
\hline Cognitive & SCSI & No definition was provided. & Primary \\
\hline Cognitive avoidance & $\begin{array}{l}\text { CCSC/ } \\
\text { HICUPS }\end{array}$ & $\begin{array}{l}\text { "This includes efforts to avoid thinking about the problem. It includes the use of fantasy or wishful } \\
\text { thinking or imagining that the situation was better. It refers to cognitive activity and not behaviors one } \\
\text { does to avoid thinking about it" (Ayers et al., 1996, p. 930). Conceptualized as a coping strategy under } \\
\text { "avoidance" coping. }\end{array}$ & Primary \\
\hline Cognitive decision making & $\begin{array}{l}\text { CCSC/ } \\
\text { HICUPS }\end{array}$ & $\begin{array}{l}\text { "This refers to planning or thinking about ways to solve the problem. It includes thinking about choices, } \\
\text { thinking about future consequences, and thinking of ways to solve the problem. It is not simply thinking } \\
\text { about the problem but thinking about how to solve it. It involves the planning and not the execution of } \\
\text { actions to solve the problem" (Ayers et al., 1996, p. 930). Conceptualized as a coping strategy under } \\
\text { "active" coping. }\end{array}$ & Primary \\
\hline Cognitive distraction & $P C Q$ & $\begin{array}{l}\text { No definition was provided. Conceptualized as a coping strategy under "problem-focused avoidance" } \\
\text { coping }\end{array}$ & Primary \\
\hline Cognitive refocusing & $\mathrm{PPCl}$ & $\begin{array}{l}\text { "An active cognitive process to focus one's attention away from pain perception, rather than simply } \\
\text { distraction which may imply a more reactive cognitive response to external stimuli" (Varni et al., 1996, } \\
\text { p. 148). }\end{array}$ & Primary \\
\hline
\end{tabular}


TABLE 4 | Continued

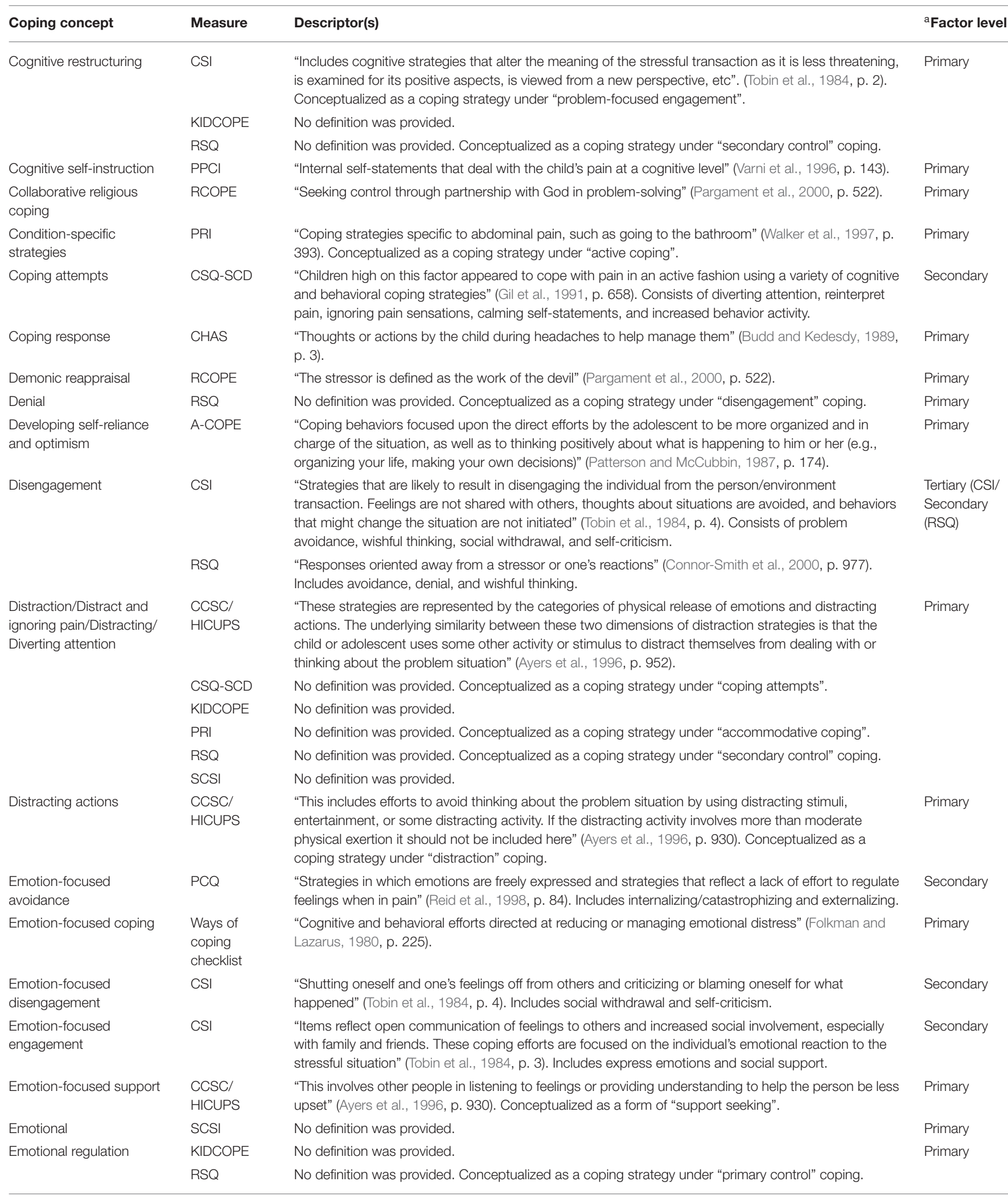


TABLE 4 | Continued

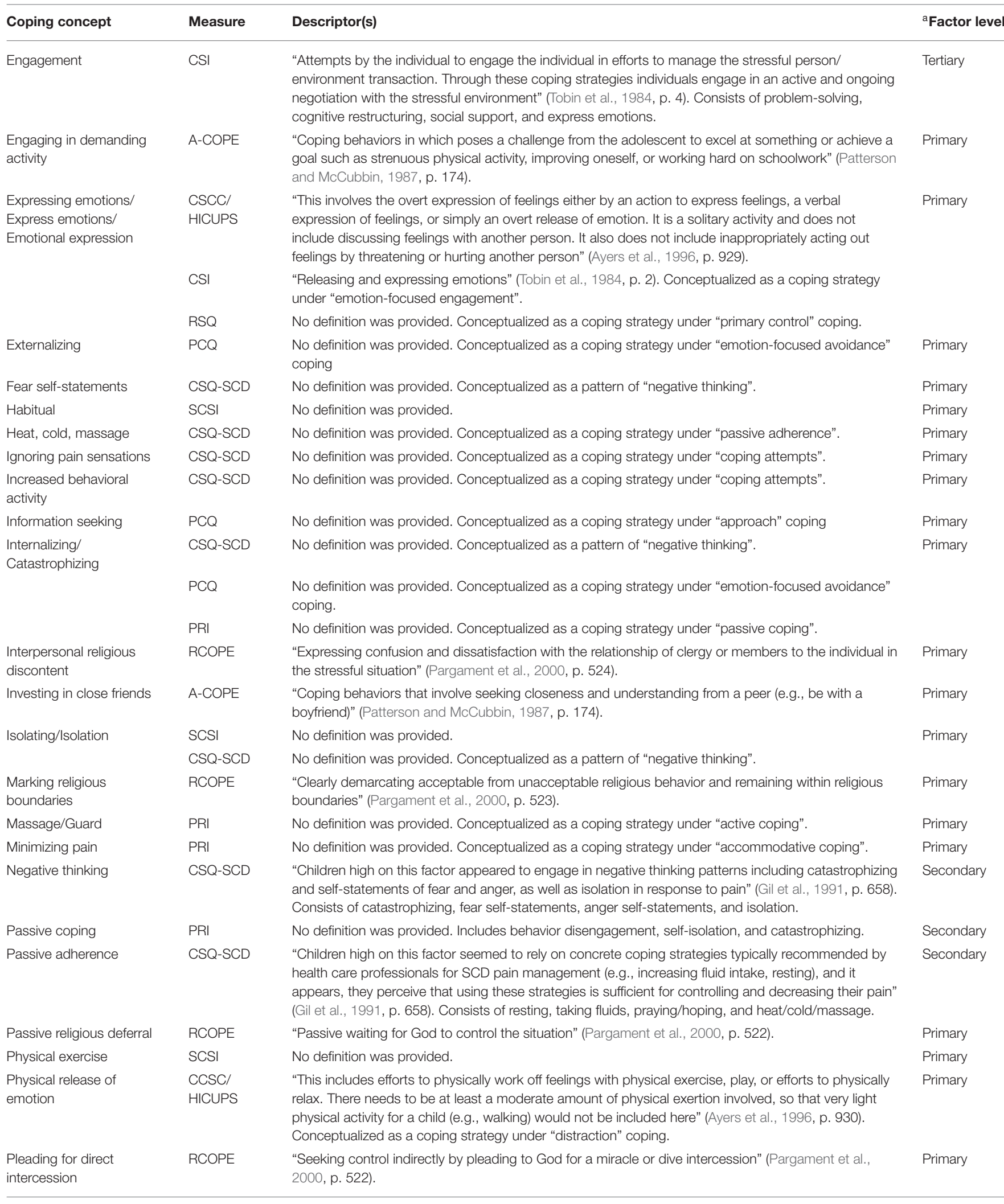


TABLE 4 | Continued

\begin{tabular}{|c|c|c|c|}
\hline Coping concept & Measure & Descriptor(s) & ${ }^{\mathrm{a}}$ Factor level \\
\hline $\begin{array}{l}\text { Positive cognitive } \\
\text { restructuring }\end{array}$ & $\begin{array}{l}\text { CCSC/ } \\
\text { HICUPS }\end{array}$ & $\begin{array}{l}\text { "This refers to thinking about the situation in a more positive way. It includes thoughts that minimize the } \\
\text { problem or the consequences of the problem. Acceptance that one can live with the situation the way } \\
\text { it is optimistic thinking and an example of positive cognitive restructuring" (Ayers et al., 1996, p. 929). } \\
\text { Conceptualized as a coping strategy under "active" coping. }\end{array}$ & Primary \\
\hline Positive self-statements & PCQ & No definition was provided. Conceptualized as a coping strategy under "approach" coping. & Primary \\
\hline Positive thinking & RSQ & No definition was provided. Conceptualized as a coping strategy under "secondary control" coping. & Primary \\
\hline Problem avoidance & CSI & $\begin{array}{l}\text { "The denial of problems and the avoidance of thoughts or action about the stressful event" (Tobin } \\
\text { et al., 1984, p. 2). Conceptualized as a coping strategy under "problem-focused disengagement". }\end{array}$ & Primary \\
\hline $\begin{array}{l}\text { Problem-focused } \\
\text { avoidance }\end{array}$ & $\mathrm{PCQ}$ & $\begin{array}{l}\text { "Attempts to disengage from the pain" (Reid et al., 1998, p. 84). Includes cognitive and behavioral } \\
\text { distraction. }\end{array}$ & Secondary \\
\hline $\begin{array}{l}\text { Problem-focused } \\
\text { engagement }\end{array}$ & CSI & $\begin{array}{l}\text { "Items involve cognitive and behavioral strategies to change the situation or to change the meaning of } \\
\text { the situation for the individual. These coping efforts are focused on the stressful situation itself" (Tobin } \\
\text { et al., 1984, p. 4). Includes problem-solving and cognitive restructuring. }\end{array}$ & Secondary \\
\hline Problem-focused support & $\begin{array}{l}\text { CCSC/ } \\
\text { HICUPS }\end{array}$ & $\begin{array}{l}\text { "Use of other people as resources to assist in seeking solutions, seeking advice/information or direct } \\
\text { task assistance" (Ayers et al., 1996, p. 930). Conceptualized as a form of "support seeking". }\end{array}$ & Primary \\
\hline \multirow[t]{2}{*}{$\begin{array}{l}\text { Problem-solving/Direct } \\
\text { problem solving }\end{array}$} & $\begin{array}{l}\text { CCSC/ } \\
\text { HICUPS }\end{array}$ & $\begin{array}{l}\text { "This refers to efforts to change the problem situation by changing the self or by changing the } \\
\text { environment. It involves what one does, not what one thinks"(Ayers et al., 1996, p. 929). } \\
\text { Conceptualized as a coping strategy under "active" coping }\end{array}$ & Primary \\
\hline & $\mathrm{CSI}$ & $\begin{array}{l}\text { "Behavioral and cognitive strategies designed to eliminate the source of stress by changing the } \\
\text { stressful situation" (Tobin et al., 1984, p. 2). Conceptualized as a coping strategy under } \\
\text { "problem-focused engagement". }\end{array}$ & \\
\hline Punishing God reappraisal & RCOPE & $\begin{array}{l}\text { "Redefining the stressor as a punishment from God for the individual's sins" (Pargament et al., 2000, p. } \\
\text { 522). }\end{array}$ & Primary \\
\hline Purification/forgive-ness & RCOPE & "Searching for spiritual cleansing through religious actions" (Pargament et al., 2000, p. 523). & Primary \\
\hline $\begin{array}{l}\text { Reappraisal of God's } \\
\text { power }\end{array}$ & RCOPE & "Redefining God's power to influence the stressful situation" (Pargament et al., 2000, p. 523). & Primary \\
\hline Reinterpret pain & CSQ-SCD & No definition was provided. Conceptualized as a coping strategy under "coping attempts". & Primary \\
\hline Relaxing & A-COPE & $\begin{array}{l}\text { "Coping behaviors which focus on ways to reduce tension such as daydreaming, listening to music, or } \\
\text { riding around in a car" (Patterson and McCubbin, 1987, p. 174-175). }\end{array}$ & Primary \\
\hline $\begin{array}{l}\text { Religious direction/ } \\
\text { conversion }\end{array}$ & RCOPE & $\begin{array}{l}\text { "Looking to religion for assistance in finding a new direction for living when the old one may no longer } \\
\text { be viable/looking to religion for a radical change in life" (Pargament et al., 2000, p. 524). }\end{array}$ & Primary \\
\hline Religious focus & RCOPE & "Engaging in religious activities to shift focus from the stressor" (Pargament et al., 2000, p. 523). & Primary \\
\hline Religious helping & RCOPE & "Attempting to provide spiritual support and comfort to others" (Pargament et al., 2000, p. 524). & Primary \\
\hline Resignation & KIDCOPE & No definition was provided. & Primary \\
\hline \multirow[t]{2}{*}{ Rest/Resting } & CSQ-SCD & No definition was provided. Conceptualized as a coping strategy under "passive adherence". & Primary \\
\hline & PRI & No definition was provided. Conceptualized as a coping strategy under "active coping". & \\
\hline $\begin{array}{l}\text { Secondary control } \\
\text { engagement }\end{array}$ & $\mathrm{RSQ}$ & $\begin{array}{l}\text { "Focused on adaptation to the problem" (Connor-Smith et al., 2000, p. 977). Includes positive thinking, } \\
\text { cognitive restructuring, acceptance and distraction. }\end{array}$ & Secondary \\
\hline Seeking diversions & A-COPE & $\begin{array}{l}\text { "Coping behaviors focused upon the adolescent's efforts to keep busy and engage in relatively sedate } \\
\text { activities that are a way to escape from or forget about the sources of tension and stress such as } \\
\text { sleeping, watching TV or reading" (Patterson and McCubbin, 1987, p. 174). }\end{array}$ & Primary \\
\hline
\end{tabular}


TABLE 4 | Continued

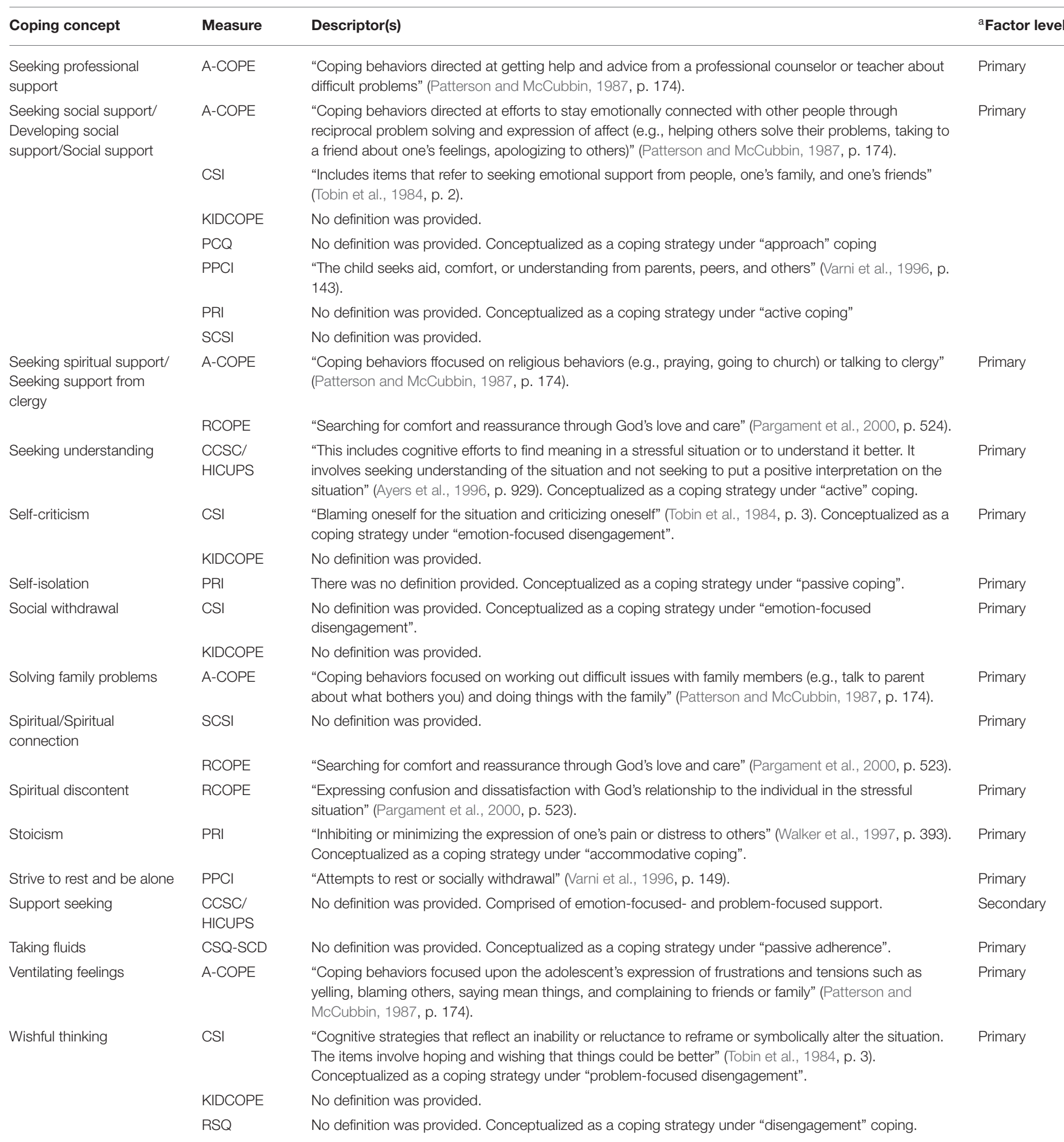

For coping responses captured by multiple questionnaires, descriptors are provided adjacently for ease of comparison. Coping responses are classified as primary, secondary, and tertiary factors based on factor analytic results from the scale development studies. A-COPE, adolescent coping orientation for problem experiences; CSI, coping strategies inventory; CSQ, coping strategies questionnaire; CCSC, children's coping strategies checklist; CHAS, children's headache assessment scale; HICUPS, how I coped under pressure scale; PCQ, pain coping questionnaire; PPCl, pediatric pain coping inventory; PRI, pain response questionnaire; RSQ, response to stress questionnaire; SCSI, schoolagers coping strategies inventory. aAn ordered-categorical scale derived from factor analytic results from the scale development studies was used to classify coping responses. The terms "primary", "secondary", and "tertiary" correspond to first-, second-, and third-order factor levels, respectively [see Results section "Aim 3: Evaluations of Measurement and Conceptual Consistency (Questionnaires Only), subsection "Classifications"]. 


\section{Measurement Consistency}

A

\section{Pain Coping Questionnaire (n $=\mathbf{2 8}$ studies:}

\section{B Coping Strategies Questionnaire ( $n$ $=21$ studies):}

\section{Pain Response Inventory $(\boldsymbol{n}=$ 19):}
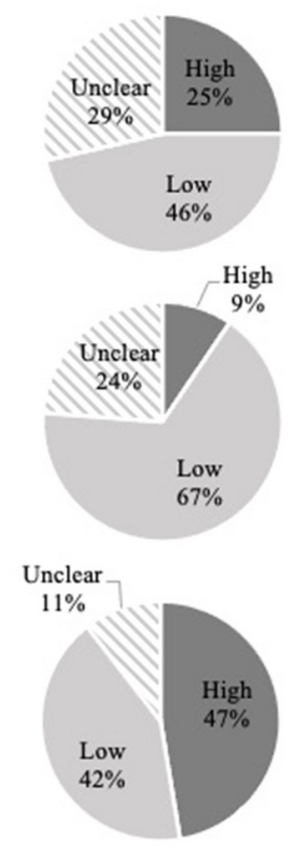
D Pediatric Pain Coping Inventory (English version only; $n=4$ )

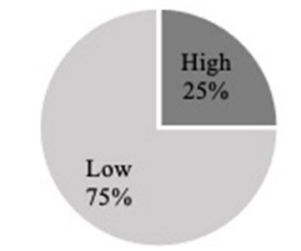

E $\quad$ KidCope $(n=6)$ :

\section{Conceptual Consistency}
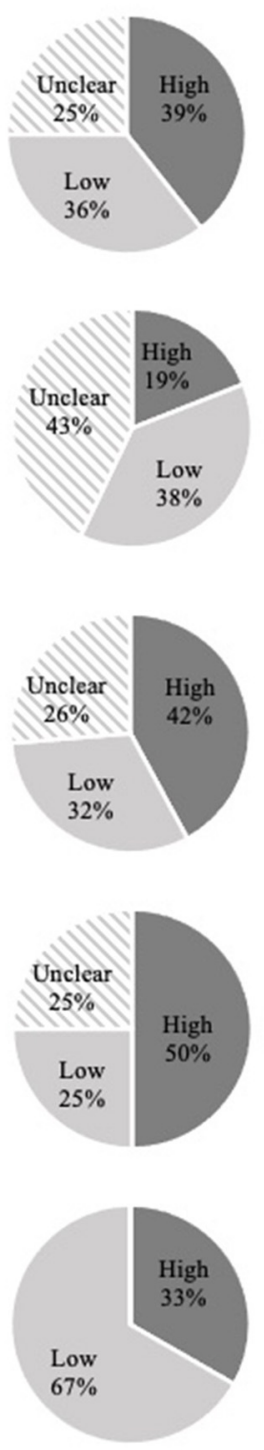

FIGURE 3 | For each measure, overall measurement and conceptual consistency ratings are presented as the percentage (\%) of studies that were classified as "high" $=$ no discrepancies, "low" = one or more discrepancies, and "unclear" = unable to evaluate (see full text, Table 1). Charts show the frequency distribution for both consistency ratings for the five most frequently cited questionnaires: (A) pain coping questionnaire; (B) coping strategies questionnaire; (C) pain response inventory; (D) pediatric pain-coping inventory (English version); and (E) KidCope. "Low" ratings indicate the presence of discrepancies that may impact our ability to directly interpret, consolidate, and/or compare research findings. These ratings do not reflect the quality of the research.

\section{Types of Discrepancies}

A wide range of discrepancies was identified in the measurement and conceptualization of coping responses by questionnaires across studies. Ratings of measurement and conceptual consistency (Figure 3), and the types of discrepancies (Supplementary Table 5) are summarized for the top five most frequently used questionnaires: PCQ (Reid et al., 1998), CSQ (Gil et al., 1991), PRI (Walker et al., 1997), PPCI (Varni et al., 1996), and KidCope (Spirito et al., 1988, 1991). These five questionnaires were used in $82.7 \%$ of studies which employed a questionnaire with known psychometric properties and 64.8\% of all included studies. As such, the coping responses assessed by these measures were the focus. Given that the remaining questionnaires were included in few studies, our ability to draw conclusions about their conceptual and measurement consistency is limited and therefore, will not be explored in detail.

\section{Pain Coping Questionnaire}

Consistent with previous reviews (Blount et al., 2008), the PCQ was the most widely used measure of coping in the context of pediatric chronic pain (ages $7-17 ; n=28$ ). The 
PCQ has been used in English (Reid et al., 1998) (24 studies), Dutch (Bandell-Hoekstra et al., 2002) (two studies), and Danish (Thastum et al., 1999) (two studies) samples. Twenty studies provided sufficient information about the PCQ to evaluate measurement consistency, of which $65 \%(n=13)$ were found to have at least one discrepancy. Types of discrepancies included using samples outside of the recommended age range of 7-17 years $(n=12)$; alternate composite scores/subscales $(n=6)$; missing one or more subscales $(n=2)$; using different coding for response options $(n=2)$; and using the sum of itemlevel responses instead of the mean $(n=1)$. Low conceptual consistency was found for $47.6 \%(n=10)$ of studies using the PCQ that provided descriptors of the coping responses assessed $(n=21)$. A common discrepancy included the inconsistent categorization of positive self-statements as a type of "problemfocused avoidance" instead of "approach" coping $(n=3)$. In addition, several studies used different labels for coping constructs, such as "distraction" instead of "problem-focused avoidance" ( $n=4)$ and "positive approach" in place of "approach coping" $(n=1)$.

\section{Coping Strategies Questionnaire for Sickle Cell Disease}

Of the studies that provided sufficient information about the measurement characteristics of the coping strategies questionnaire for sickle cell disease (CSQ-SCD) $(n=16), 87.5 \%$ ( $n=14$ ) had at least one discrepancy. The most common discrepancy was the inclusion of participants beyond the age range of the scale development study (i.e., 7-17 years old; $n=$ 13). Other discrepancies included using participants with a pain condition other than $\operatorname{SCD}(n=2)$; alternate composite scores (e.g., total coping attempts, rational thinking; $n=3$ ); missing subscales $(n=1)$; using a six- instead of seven-point Likert scale $(n=2)$; using a 44 -item version of the CSQ-SCD $(n=2)$; and/or computing subscales by taking the sum of the item-level responses instead of the mean $(n=2)$. Conceptual consistency was evaluated for 12 of the included studies that used the CSQSCD. Of these studies, $66.7 \%(n=8)$ reported a discrepancy in their conceptualization of particular coping responses. The primary reason for low ratings of conceptual consistency was the use of alternate terminology for constructs operationalized by the CSQ-SCD $(n=4)$. For example, the terms "illnessfocused strategy" and "adherence" have been used in place of "passive adherence".

\section{Pain Response Inventory}

Upon evaluating measurement consistency ( $n=17), 47.1 \%$ $(n=8)$ of studies had more than one discrepancy. The reasons for low ratings of measurement consistency included the following: the inclusion of participants outside of the age range of the PRI validation sample (i.e., 7-17 years old; $n=3$ ); used in a sample of youth with pain conditions other than abdominal pain $(n=2)$; computing subscales by taking the sum of the item-level responses instead of the mean $(n=1)$; missing subscales $(n=4)$; and/or alternate categorizations of subscales $(n=1)$. Conceptual consistency was evaluated for 14 studies using the PRI. The original scale development study of the PRI did not provide definitions of the coping constructs assessed, and therefore, conceptual consistency was evaluated by the inclusion of specific examples of coping strategies that fall within each of the higher-order factors. As such, a common discrepancy was the exclusion or incorrect categorization of lower-order subscales in the conceptualization of higher-order ones ( $n$ $=5$ ). For example, several studies excluded "stoicism" in the conceptualization of "accommodative coping" $(n=3)$. In addition, inconsistent labeling of coping responses was demonstrated by one study that used the term "activity restriction" in place of "behavior disengagement".

\section{Pediatric Pain Coping Inventory}

Measurement and conceptual consistency could not be evaluated for studies that used the German version of the Pediatric Pain Coping Inventory (PPCI) because the scale development study was not available in English. As a result, four studies were used to evaluate measurement and conceptual consistency for the PPCI. In terms of measurement consistency, $75 \%$ of studies that used the PPCI $(n=3)$ were rated "low". Types of discrepancies included the inclusion of participants beyond the intended age range (i.e., $5-16$ years old; $n=2)$ and pain type $(n=1)$ validated for the PPCI. Moreover, conceptual consistency was rated "low" for one study (25\%) that used the PPCI. This study reported using the a priori coping responses ("distraction", "problemsolving", and "helplessness") as opposed to those supported by factor analysis and psychometric properties of the PPCI assessed in children with chronic pain ("strive for rest and be alone", "cognitive refocusing", and "problem-solving selfefficacy").

\section{KidCope}

The majority of the six studies (83.3\%) that employed the KidCope were rated low for measurement consistency. The most common discrepancy was the inclusion of participants aged two or more years outside of the age range validated for the KidCope (i.e., child version $=9-13$; adolescent version $=12-18$ ) $(n=5)$. While the KidCope was developed as a unidimensional scale, two studies computed alternate higher-order scores using the coping strategies measured by the KidCope. In addition, one study used a four-point Likert scale for the adolescent version rather than the original "yes/no" response items. With regard to conceptual consistency, $66.7 \%$ of studies that used the KidCope were rated as "low". Two studies proposed using the coping responses assessed by the KidCope to conceptualize "active" and "passive" coping; and, in contrast, one other study conceptualized "negative/avoidance" and "positive/approach". Neither of these higher-order conceptualizations of coping responses was proposed in the development of the KidCope. In another study, discrepancies included mislabeling coping responses (e.g., using the term "withdrawal" in place of "social withdrawal") or adding coping responses that are not typically conceptualized by the KidCope (i.e., remain positive, blame self instead of self-criticism, express emotions, relax, become helpless, different feelings, focus on future, taking medication/laying down). 


\section{DISCUSSION}

This scoping review is the first to examine the sample and methodological characteristics, theoretical frameworks, and measurement tools used to measure and conceptualize coping in pediatric chronic pain. Overall, a lack of theory, conceptual clarity, conceptual consistency, and measurement consistency emerged in included studies. In the discussion, these results and their implications are explored in relation to four major gaps and are drawn upon to offer recommendations for future research.

\section{Gap 1: Lack of Theory, Conceptual Clarity, and Conceptual Consistency}

It is important for researchers to ground their research questions and methods in theory to ensure an appropriate use of measures and concepts. Also, explicit use of theory helps readers to make sense of and interpret findings. Less than 13\% of included studies provided a clear explanation of a theoretical framework for the coping responses assessed. Even fewer studies (7\%) used theory to justify the research methods employed. Current theoretical frameworks focus on the conceptualization of higherorder coping responses (i.e., secondary factors such as emotionfocused vs. problem-focused coping, tertiary factors such as engagement vs. disengagement) and organize lower-order coping responses within them (i.e., primary factors). The overreliance on quantitative and exploratory methods has contributed to an excessive number of lower-order conceptualizations (86 primary coping responses) that makes it challenging to synthesize, interpret, and apply this literature in future research and clinical contexts. Thus, theoretical frameworks for primary coping responses are needed to clearly and consistently operationalize overt thoughts and behaviors used for coping. Building and incorporating strong theoretical frameworks could help to establish a more parsimonious literature by avoiding redundant and synonymous conceptualizations (e.g., "ventilating feelings" and "expression of emotion").

The use of the terms "coping styles" to refer to higher-order categories was not as prominent as expected, and $75 \%$ of studies that focused on conceptualizing higher-order categories did not use any particular coping terminology to describe them. As such, a more explicit use of theory can also bring clarity and consistency to the conceptualization of higher- vs. lower-order categories of coping responses. For example, some researchers might use dispositional/stylistic categories, such as "coping styles", if the recommendation is to view coping responses as being stable over time and situation (Moos and Holahan, 2003). In contrast, researchers might avoid specific or highly restrictive terminology when using a contextual perspective, wherein coping responses are used differently in response to developmental (e.g., maturity) and environmental factors (e.g., access to resources) (Roberts et al., 2001; Moos and Holahan, 2003; Kim-Cohen et al., 2004). An integrative perspective might view some coping responses as stable and others as flexible over time and situations. As a field, it is important to further explore whether a particular theory or an integrative approach could drive a more clear and consistent understanding of the terminology used to refer to hierarchical classifications of coping responses.
Almost half of the included studies did not explicitly state descriptors of the coping responses assessed. Also, a third of the studies that used questionnaires described coping responses in a way that was inconsistent with the original scale development study, such as using a different definition(s), categorizations of lower-order into higher-order coping responses, or alternate terminologies for referring to factors. One issue contributing to low conceptual clarity and consistency is the tendency for authors to describe coping responses based on their relationship with coping outcomes rather than the nature or operationalization of the thoughts or behaviors underlying the coping response. For example, some authors have described both "passive coping" and "passive adherence" solely by their associations with maladaptive outcomes in youth with chronic pain (e.g., Thompson et al., 1994; Logan et al., 2012). This description is problematic for two main reasons. First, coping responses have inconsistent relationships with coping outcomes, and the factors contributing to these inconsistencies are not well-understood (Skinner et al., 2003; Zimmer-Gembeck and Skinner, 2016). Therefore, while "passive coping" and "passive adherence" are generally associated with negative outcomes, this might not be consistent across studies, individuals, or contexts. Second, relying on this description alone does not provide any information about what it looks like for a youth to use either of these coping responses and can lead to confusion between these two terms that are conceptually distinct (for an example, see Figure 1). While the adaptive and maladaptive qualities of coping responses are relevant to their conceptualization, researchers should prioritize using definitions and examples in their papers that help readers to reproduce these concepts in research and discuss them in clinical practice.

\section{Gap 2: Lack of Diverse Research Methods and Measurement Consistency}

Most of our knowledge about coping in the context of pediatric chronic pain is based on quantitative methods ( $85 \%)$ and crosssectional designs (67\%) with an emphasis on parent- and/or selfreport questionnaires to assess coping responses in youth (86\%). The five most common questionnaires identified were four painspecific coping questionnaires (i.e., PCQ, PRI, PPCI, and CSQSCD) and one general coping questionnaire (i.e., KidCope). The use of questionnaires to assess coping is, generally, a cost-effective and convenient method for data collection. Some questionnaires (e.g., PCQ, KidCope) are available in different versions (e.g., language, age, and pain condition), enabling more tailored selection. Moreover, questionnaires can be used to promote more consistent conceptualizations of coping in the literature and allow for the consolidation of research findings across studies if used frequently and consistently by study authors. Unfortunately, regarding measurement consistency, just over half of studies had one or more discrepancies, and one in five was missing more than two relevant scale characteristics. However, as we employed a strict criterion for measurement consistency, a "discrepancy" does not necessarily mean that the study was flawed or inaccurate but rather highlights an inconsistency between studies that may impact our ability to directly consolidate and/or compare research findings. In addition, the high proportion of studies 
missing information about the scale in their methods highlights a lack of transparency in the literature, which in turn, limits the reproducibility of studies and the ability to confidently consolidate findings across studies. The less we can consolidate findings, the less we can advance the field both in terms of theory building and testing as well as interventions.

Another potential limitation of questionnaires is the possibility for psychometric inadequacies, including an unstable or unsubstantiated factor structure (e.g., over-factoring, poor reproducibility), inadequate or non-existent construct validity, and no reports of test-retest reliability (Parker and Endler, 1992; Blount et al., 2008). Additionally, the use of exploratory factor analytic procedures contributes to an abundance of complex and difficult-to-interpret constructs that lack clinical utility and relevance (Parker and Endler, 1992; Blount et al., 2008). While overarching categories of coping responses (i.e., factors) can be useful for understanding and predicting coping outcomes, these constructs can be abstract and difficult to operationalize in the development of interventions (Blount et al., 2008). As such, Blount and colleagues (Blount et al., 2008) highlighted the importance of assessing and reporting on discrete, trainable mental actions or behaviors. One approach to assessing specific coping behaviors is by analyzing and interpreting item-level responses on questionnaires (Blount et al., 2008; Schwartz, 2016). For example, using the PCQ, researchers and clinicians might examine group or individual differences in responses to "talk to a family member about how I feel" and "talk to a friend about how I feel" instead of the subscale score for "seeking social support". This information helps to understand the specific ways that social support is used by youth to cope with pain. Although item-level responses are less psychometrically sound and provide less information about the latent variable being measured, they can be relevant to intervention studies where outcomes are used to inform intervention training and clinical recommendations. Alternatively, behavioral assessment tools are useful for assessing discrete, overt coping behavior (e.g., observable body movements, sounds, and words), which can be advantageous for identifying and monitoring specific behaviors, overcoming barriers to self-report (e.g., social desirability), and working with youth who have complex developmental or intellectual disabilities. To date, in contrast to acute pain, there are no well-established behavioral coping measures for pediatric chronic pain (Blount et al., 2008; Chorney and McMurtry, 2014), and therefore, developing such tools is an important direction for future research.

\section{Gap 3: Poor Understanding of Coping Responses in Diverse Patient Populations}

Although participant characteristics varied across studies in terms of age (3-20 years) and pain conditions, the lack of research in specific patient populations limits the validity of current measurement tools and conceptualizations of coping responses in certain populations. There is evidence to suggest that the use of coping responses may be influenced by age (Curry and Russ, 1985; Compas, 1998; Dubow and Rubinlicht, 2011). For example, young children may rely more on parental support for coping, whereas adolescents have a greater capacity for using more cognitive-oriented coping responses (e.g., cognitive restructuring) and for seeking a broader array of informational, emotional, and tangible supports beyond the family (Dubow and Rubinlicht, 2011). However, very few studies focused exclusively on children under 12 years with chronic pain $(8 \%)$, and most studies included both child and adolescent participants (68\%). Of note, no studies on coping in infants and toddlers with chronic pain were identified nor measures with known psychometric properties for children under 5 years. It is unclear whether this lack of research stems from actual low prevalence of chronic pain in infants (estimated at 1-3\%) (Perquin et al., 2000; King et al., 2011) or challenges with detecting and adequately describing chronic pain in infancy (Pillai Riddell et al., 2009; DiLorenzo et al., 2016). Also, current models of conceptualizing coping responses as voluntary/intentional thoughts or actions may be inappropriate to understand infant coping as they have limited cognitive and language capacity as well as learned experiences to independently implement coping responses or describe their ways of coping. More nuanced research is needed to better understand how coping responses may change across development.

Studies were primarily conducted in the United States or Europe $(88 \%)$ and included predominately female participants (65\%). Apart from studies focused on youth with sickle cell disease [which primarily affects individuals of African or Caribbean descents (Hassell, 2010)], the majority of studies that reported on race/ethnicity included white participants (93\%). This highlights a lack of measurement and conceptualization of coping responses in diverse cultural (i.e., cross-national, crossethnic, and cross-racial cultures) and/or sex/gender groups of youth with chronic pain. A systematic review of the adult chronic pain literature suggests that mean scores on measures of pain-related coping responses vary significantly between people of different countries and languages (Sharma et al., 2020). In addition, cultural and contextual theories of coping highlight that while stress and coping, in general, are universal experiences, members of different cultures might not only experience different/additional stressors but also consider and respond to stressors differently with respect to coping goals, responses, and outcomes (Kuo, 2011). For example, members of individualistic cultures tend to prioritize "externally targeted control" (i.e., changing the environment/stressor), whereas members of collectivistic culture tend to use "internally targeted control" (i.e., changing oneself) (Kuo, 2011). This highlights the importance of understanding which coping responses are relevant to assess and recommend for diverse youth.

Although there is evidence for sex-specific engagement in coping responses among adolescents with chronic pain (e.g., females reported greater use of social support networks than males) (Keogh and Eccleston, 2006), this research has not explored the biological and sociocultural mechanisms for these group differences. A poor understanding of the underlying mechanisms of sex differences and the interchangeable use of the terms "gender" and "sex" in this research poses risks for sexbased stereotypes regarding the effectiveness of certain coping responses that may not be consistent with individual preferences 
and/or gender identity (Boerner et al., 2018; Samulowitz et al., 2018). Important gaps to be addressed in the literature include considering the role of gender identity/expression in coping as well as to make clear in research papers when birth-assigned sex vs. self-identified gender is being reported.

\section{Gap 4: Lack of Measurement Tools and Conceptualizations for Proactive Coping}

Few studies $(<6 \%)$ assessed proactive coping responses using either interview or daily diary-recorded measures. Although research on proactive coping is limited in youth (Schwarzer and Luszczynska, 2008), studies in adults demonstrate that proactive coping is associated with various positive psychological (e.g., higher life satisfaction) and physical outcomes (e.g., rehabilitative functioning) (Katter and Greenglass, 2013; Miao et al., 2017; Bhattacharyya et al., 2018). Moreover, the concept of proactive coping is consistent with the push for long-term behavioral changes in the management of chronic pain (Landry et al., 2015; Miró et al., 2017). Taken together, proactive coping is deemed a promising approach to coping for youth with chronic pain.

To advance our ability to assess proactive coping, it is important to first clarify how to conceptualize proactive coping responses via theory. Thus, more qualitative research in this area would be useful for identifying different proactive coping responses. Based on this information, the next step would be to derive appropriate assessment tools that capture these responses. To date, the proactive coping inventory (PCI) (Greenglass et al., 1999) for adults is the only known questionnaire for assessing proactive coping responses. Perhaps, the adult-focused literature on proactive coping stems from the need for individuals to be able to anticipate pain-related stressors and independently implement lifestyle changes. As such, self-report assessments may be useful for older youth who may have accumulated experience with chronic pain and can take an active role in implementing lifestyle changes. In contrast, researchers may consider the role of parents in assessments for young children. A greater capacity for understanding and assessing proactive coping in the youth of all ages holds promise for preventing the impact of chronic pain on overall health and psychosocial well-being.

\section{Recommendations for Future Research}

The following sections of this review outline a proposed three-step process (Figure 4) for establishing more clarity and consistency in the literature.

\section{Step One: Theory Testing/Validation and Revision}

There is a critical need for more explicit, well-developed theories of coping in the pediatric chronic pain literature that can then provide the knowledge base for construct validation (Strauss and Smith, 2009). Theoretical frameworks serve as a rationale for why we measure particular coping responses by clarifying their meaning and conceptual relationships. Theories need to be culture specific and patient centered (Kuo, 2011). In addition, advancements in theory should clarify how we think about and relate higher- and lower-order coping responses (e.g., dispositional vs. conceptual frameworks).
Current theories of coping used in pediatric chronic pain research were derived from adult or non-chronic pain populations and were rarely cited in the research literature. As such, two pertinent steps need to be taken. First, considering that theory testing/validation is an iterative process (Strauss and Smith, 2009), there is a need for research aimed at either re-evaluating and revising current theoretical models of pain-related coping responses to be applicable to pediatric chronic pain or beginning anew. In these efforts, ways of conceptualizing proactive coping responses should be explored. Assimilating qualitative and/or observational methodologies may prove particularly helpful to test theoretical mechanisms and better capture the lived experiences of youth with chronic pain (Tutelman and Webster, 2020).

Second, it is important to recognize that theories and data are independent of each other (Strauss and Smith, 2009); therefore, researchers are responsible for drawing connections between their findings and theory to improve the clarity and consistency of literature. This would include using more explicit statements of theory and definitions in the introduction or the discussion section of a paper that would: (i) clarify the relevance of particular coping responses to the population of interest; (ii) justify the use of a given measure; (iii) promote a mutual understanding of research findings; and (iv) inform future efforts toward theory validation (Parker, 2020). The underuse or superficial use of theories and definitions in papers may relate, in part, to manuscript length restrictions put in place by publishers. In these situations, authors should consider the use of supplementary materials or open access repositories to share additional conceptual information needed.

\section{Step Two: Measure Development, Evaluation, and Modification}

Clear and well-defined theories should be used to guide how we measure coping responses. Although the development of new theories may dictate the need for new measures, researchers should, first, carefully consider whether existing measures can be adapted to fit new/modified theories. Adapting existing measures would be beneficial for reassessing the validity of former coping responses, avoiding the creation of redundant or interchangeable coping responses, and comparing new and extant research. More parsimonious literature can also be established by crossvalidating or performing content analyses between different coping measures (Crombez et al., 2020). Measures of coping should be tested and periodically re-evaluated in samples of youth with chronic pain, which, in turn, may serve to validate and/or revise the theoretical frameworks used. As such, the process of developing/modifying and evaluating measures (Step 2) should be iterative and interactive with theory construction (Step 1).

This review highlights the need for research aimed at evaluating the reliability, validity, and clinical utility of measures and conceptualizations of coping responses in different age, gender, and cultural groups. In other fields, the use of item content analyses, focus groups, or cognitive interviews has been useful for capturing group differences and patient experiences using particular measures (Beatty and Willis, 2007; Amtmann 


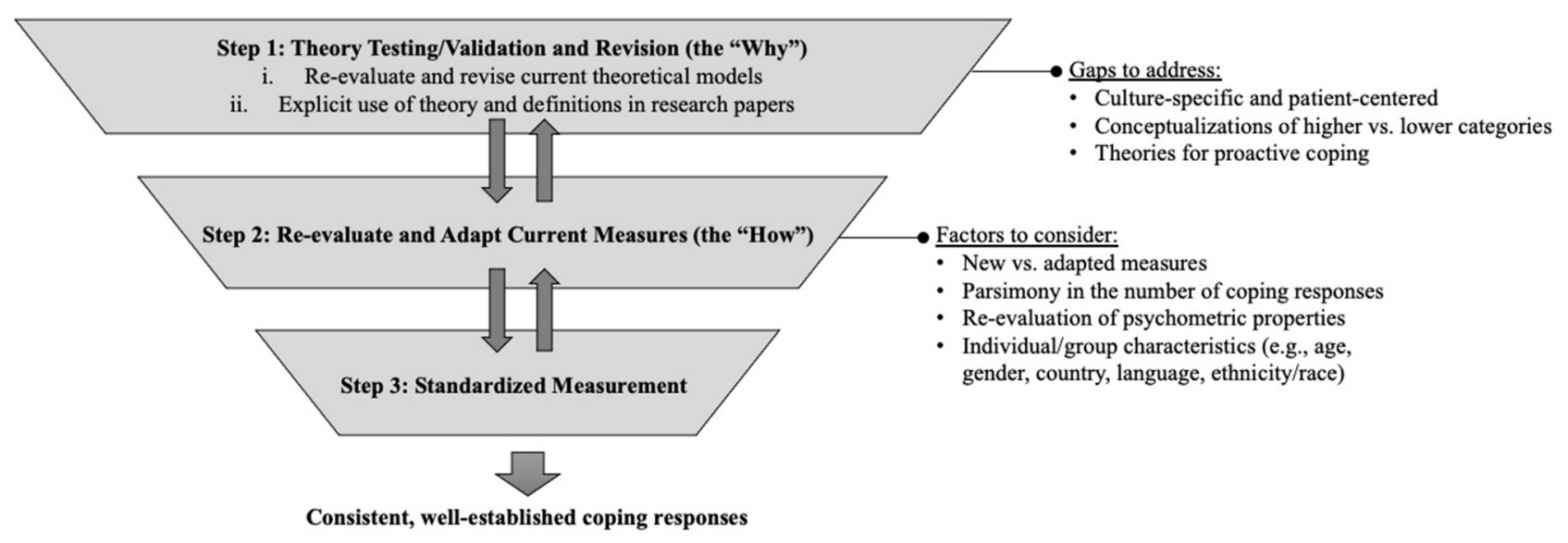

FIGURE 4 | Proposed three steps for future research aimed at establishing more consistent, well-defined coping responses. Double arrows indicate the iterative and interactional relationship between steps.

et al., 2018; Crombez et al., 2020). Researchers have also used culture-specific and patient-centered approaches for recruitment to increase the diversity of youth in research (Zamora et al., 2016; Winter et al., 2018). Alternatively, the recruitment of sufficient sample sizes can allow for age, gender, and ethnicity-specific analyses (Winter et al., 2018).

\section{Step Three: Standardized Measurement}

Once the field develops fewer, more well-established measures with clearly defined coping responses grounded in theory, researchers may consider the benefits of using a publicly available registry. This uniform approach has been adopted by the patient-reported outcomes measurement information system (PROMIS $\AA$ ) to measure pain sensations (i.e., intensity and quality), interference, and behaviors in the context of chronic pain (Jacobson et al., 2015; Askew et al., 2016; Witter, 2016; Singh et al., 2019). Registered coping measures specific to youth with chronic pain may help to establish a unified understanding of coping, meaningful and relevant measurement tools, and comparability across studies.

\section{Recommendations for Clinical Practice}

Although considerable work is needed to improve the clarity and clinical utility of the pediatric pain-coping literature, this review can serve as a resource for clinicians. For instance, clinicians can use this review to: (1) access a list of specific coping responses; (2) locate relevant research; and (3) identify and select measures for assessing the use of pain-coping responses in youth. However, there is currently, no best way to measure and conceptualize coping responses in this population. Instead, clinicians are encouraged to select measurement tools that have strong psychometric properties when used with their target population (i.e., age, pain condition) and based on their content (e.g., specific questions). For example, the PRI was developed for use in youth with abdominal pain, and therefore, a clinician working in a gastroenterology service may implement the PRI in his or her clinical practice. Alternatively, by comparing the item-level content for "seeking social support" on the PRI and PCQ, for example, it is apparent that the PCQ is better able to distinguish between the types of companions (friends vs. family) than the PRI. Therefore, the clinician may select the measure based on the goals of his or her assessment. Regardless, clinicians are encouraged to be intentional about their measure choice. In addition, clinicians can supplement their assessments with open-ended questions that create opportunities for patients to share information about more culturally relevant and personspecific approaches to coping. Furthermore, clinicians can play an important role in building consistency to the field by using evidence-based terminologies and conceptualizations of coping responses with their patients in a way that aligns with how they are intended to be used.

\section{STRENGTHS AND LIMITATIONS}

This review is the first to evaluate the clarity and consistency of the measurement and conceptualization of coping responses in youth with chronic pain. Strengths include the comprehensive search strategy and rigorous methodology used to identify and summarize published research. The findings of this review will allow researchers to design studies to address research gaps and inform more consistent and targeted assessments and conceptualizations of coping responses.

There are also limitations. One inherent limitation of a scoping review approach is that it does not formally evaluate the quality of evidence or allow for conducting a comprehensive synthesis of research findings (Pham et al., 2014; Munn et al., 2018). Therefore, concrete guidance on how best to measure or reconceptualize coping responses in the literature is beyond the scope of this review. In addition, this review did not consider the order and mode of administration (e.g., online, paper, and verbal), which may impact the types of coping responses reported by youth (Bowling, 2005). Also, we did not include a comparison between measures; however, it is critical to consider how assessments of frequency vs. duration vs. intensity may 
influence how youth report on the same coping response (Stone et al., 1991).

Another limitation is the potential magnification of the extent of discrepancies. A set of strict criteria was used due to the lack of clarity as to which discrepancies hinder the reliability and validity of the results. For example, the most common discrepancy for measurement consistency was using a sample outside the age range validated by the scale. The extent to which a particular measure can be used in a sample of participants even 1 year outside of the age range is unclear.

Furthermore, there are factors that may have limited the breadth of this review. For instance, this review did not take into account studies that were not available in English, which may have limited the inclusion of research on geographically and ethnically diverse patient populations. In addition, coping is a nebulous concept; the distinction between thoughts and behaviors that would constitute coping as opposed to adaptation or self-management is not always obvious (Audulv et al., 2016). Likewise, coping responses are often confused with interventions for chronic pain (e.g., mindfulness training, medications, and exercise therapy) or self-care routines (e.g., getting enough sleep). Given that this review attempted to focus exclusively on studies that measured coping responses, the lack of clarity of how to differentiate coping responses from similar concepts may have led to the exclusion of relevant studies.

\section{CONCLUSION}

This review was a necessary first step toward providing concrete guidance on how best to measure or reconceptualize coping responses in the literature on pediatric chronic pain. The results demonstrate the complexity of the literature and highlight gaps and inconsistencies across studies. These gaps are underscored by the lack of theories and definitions/examples of coping responses across studies, which makes it challenging to interpret and apply research findings. Additionally, the wide range of measurement tools and inconsistencies in their use further contributes to the confusing state of this literature. It is recommended that future research prioritize the development and testing of theories and measures of coping responses for pediatric chronic pain. These efforts should be an iterative and interactive process and include a wider range of participants and cultures. Ultimately, the

\section{REFERENCES}

Amtmann, D., Liljenquist, K., Bamer, A., Bocell, F., Jensen, M., Wilson, R., et al. (2018). Measuring pain catastrophizing and pain-related self-efficacy: expert panels, focus groups, and cognitive interviews. Patient 11, 107-117. doi: $10.1007 /$ s40271-017-0269-1

Arksey, H., and O'Malley, L. (2005). Scoping studies: towards a methodological framework. Int. J. Soc. Res. Methodol. 8, 19-32. doi: 10.1080/1364557032000119616

Askew, R. L., Cook, K. F., Revicki, D. A., Cella, D., and Amtmann, D. (2016). Evidence from diverse clinical populations supported clinical validity of PROMIS pain interference and pain behavior. J. Clin. Epidemiol. 73, 103-111. doi: 10.1016/j.jclinepi.2015.08.035 implementation of standardized measures grounded in theory with clear definitions of coping responses is critical to establish clearer and more consistent conceptualizations of coping in the field.

\section{DATA AVAILABILITY STATEMENT}

The original contributions presented in the study are included in the article/Supplementary Material, further inquiries can be directed to the corresponding author/s.

\section{AUTHOR CONTRIBUTIONS}

This work was conducted as the master's thesis of ANN under the supervision of CMM. BAM is an advisory committee member. ANN, RMT, and CMM conceived the project with feedback from BAM. ANN and RMT conducted the searches. ANN analyzed results and wrote the manuscript. All authors read, edited, and approved the final manuscript.

\section{FUNDING}

This work was supported by the general purpose research account of CMM from the University of Guelph and infrastructure funded by the Canadian Foundation for Innovation and the Ministry for Research and Innovation. ANN was supported by the Ontario Graduate Scholarship (from 2019 to 2021).

\section{ACKNOWLEDGMENTS}

We would like to thank the following undergraduate research assistants, Caroline Zolis, Grace Wong, Yan Li, Noah Wright, Sonali Khera, and Grace Caya, for their assistance with screening articles for inclusion, checking data extractions, and assisting with developing the tables used in this paper.

\section{SUPPLEMENTARY MATERIAL}

The Supplementary Material for this article can be found online at: https://www.frontiersin.org/articles/10.3389/fpsyg. 2021.680277/full\#supplementary-material 
family functioning, and children's adjustment. J. Black Psychol. 25, 356-377. doi: $10.1177 / 0095798499025003006$

Beatty, P. C., and Willis, G. B. (2007). Research synthesis: the practice of cognitive interviewing. Public Opin. Q. 71, 287-311. doi: 10.1093/poq/nfm006

Bhattacharyya, D., Namdeo, M., and Dwivedi, A. K. (2018). Proactive coping style and intentional self-harm: a cross-sectional study. Ind. Psychiatry J. 27, 67. doi: 10.4103/ipj.ipj_2_18

Blount, R. L., Simons, L. E., Devine, K. A., Jaaniste, T., Cohen, L. L., Chambers, C. T., et al. (2008). Evidence-based assessment of coping and stress in pediatric psychology. J. Pediatr. Psychol. 33, 1021-1045. doi: 10.1093/jpepsy/jsm071

Boateng, G. O., Neilands, T. B., Frongillo, E. A., Melgar-Quiñonez, H. R., and Young, S. L. (2018). Best practices for developing and validating scales for health, social, and behavioral research: a primer. Front. Public Health 6, 149. doi: $10.3389 /$ fpubh.2018.00149

Boerner, K. E., Chambers, C. T., Gahagan, J., Keogh, E., Fillingim, R. B., and Mogil, J. S. (2018). Conceptual complexity of gender and its relevance to pain. Pain 159, 2137-2141. doi: 10.1097/j.pain.0000000000001275

Bowling, A. (2005). Mode of questionnaire administration can have serious effects on data quality. J. Public Health 27, 281-291. doi: 10.1093/pubmed/fdi031

Budd, K. S., and Kedesdy, J. H. (1989). Investigation of environmental factors in pediatric headache. Headache. 29, 569-573. doi: $10.1111 /$ j.1526-4610.1989.hed2909569.x

Budd, K. S., Workman, D. E., Lemsky, C. M., and Quick, D. M. (1994). The children's headache assessment scale (CHAS): factor structure and psychometric properties. J. Behav. Med. 17, 159-179. doi: 10.1007/BF018 58103

Chorney, J. M., and McMurtry, C. M. (2014). "Behavioural measures of pain", in Oxford Textbook of Paediatric Pain, eds P. J. McGrath, B. J. Stevens, S. M. Walker, and W. T. Zempsky (New York, NY: Oxford University Press), 379-390. doi: 10.1093/med/9780199642656.003.0037

Compas, B. E. (1998). An agenda for coping research and theory: basic and applied developmental issues. Int. J. Behav. Dev. 22, 231-237. doi: $10.1080 / 016502598384351$

Compas, B. E., Banez, G. A., Malcarne, V., and Worsham, N. (1991). Perceived control and coping with stress: a developmental perspective. J. Soc. Issues. 47, 23-34. doi: 10.1111/j.1540-4560.1991.tb01832.x

Compas, B. E., Jaser, S. S., Dunbar, J. P., Watson, K. H., Bettis, A. H., Gruhn, M. A., et al. (2014). Coping and emotion regulation from childhood to early adulthood: points of convergence and divergence. Aust. J. Psychol. 66, 71-81. doi: 10.1111/ajpy.12043

Compas, B. E., Jaser, S. S., Dunn, M. J., and Rodriguez, E. M. (2012). Coping with chronic illness in childhood and adolescence. Annu. Rev. Clin. Psychol. 8, 455-480. doi: 10.1146/annurev-clinpsy-032511-143108

Connor-Smith, J. K., Compas, B. E., Wadsworth, M. E., Thomsen, A. H., and Saltzman, H. (2000). Responses to stress in adolescence: measurement of coping and involuntary stress responses. J. Consult. Clin. Psychol. 68, 976-992. doi: 10.1037/0022-006X.68.6.976

Coster, W. J. (2013). Making the best match: selecting outcome measures for clinical trials and outcome studies. Am. J. Occup. Ther. 67, 162-170. doi: 10.5014/ajot.2013.006015

Crombez, G., Paepe, A. L. D., Veirman, E., Eccleston, C., and Verleysen, G. (2020). Ryckeghem DMLV. Let's talk about pain catastrophizing measures: an item content analysis. PeerJ. 8, e8643. doi: 10.7717/peerj.8643

Curry, S. L., and Russ, S. W. (1985). Identifying coping strategies in children. J. Clin. Child Psychol. 14, 61-69. doi: 10.1207/s15374424jccp1401_10

DiLorenzo, M., Pillai Riddell, R., and Holsti, L. (2016). Beyond acute pain: understanding chronic pain in infancy. Children 3, 26. doi: 10.3390/children 3040026

Dubow, E. F., and Rubinlicht, M. (2011). "Coping", in Encyclopedia of Adolescence, eds B. B. Brown and M. J. Prinstein (San Diego, CA: Academic Press). 109-118. Available online at: https://www.sciencedirect.com/science/article/ pii/B9780123739513001071 (accessed March 5, 2021).

Eccleston, C., Palermo, T. M., Williams, A. C. D. C., Holley, A. L., Morley, S., Fisher, E., et al. (2014). Psychological therapies for the management of chronic and recurrent pain in children and adolescents. Cochrane Database Syst. Rev. 2014, CD003968. doi: 10.1002/14651858.CD003968.pub4

Folkman, S., and Lazarus, R. S. (1980). An analysis of coping in a middle-aged community sample. J. Health Soc. Behav. 21, 219-239. doi: 10.2307/2136617
Garcia, C. (2010). Conceptualization and measurement of coping during adolescence: a review of the literature. J. Nurs. Scholarsh. 42, 166-185. doi: 10.1111/j.1547-5069.2009.01327.x

Gerring, J. (1999). What makes a concept good? A criterial framework for understanding concept formation in the social sciences. Polity 31, 357-393. doi: $10.2307 / 3235246$

Gil, K. M., Williams, D. A., Thompson, R. J., and Kinney, T. R. (1991). Sickle cell disease in children and adolescents: the relation of child and parent pain coping strategies to adjustment. J. Pediatr. Psychol. 16, 643-663. doi: 10.1093/jpepsy/16.5.643

Greenglass, E., Schwarzer, R., and Taubert, S. (1999). The Proactive Coping Inventory (PCI): A Multidimensional Research Instrument. Available online at: http://userpage.fu-berlin.de/ health/greenpci.htm (accessed February 4, 2021).

Hardin, A. P., and Hackell, J. M. (2017). Committee on practice and ambulatory medicine. Age limit of pediatrics. Pediatrics 140, e20172151. doi: 10.1542/peds.2017-2151

Harris, J. A., Newcomb, A. F., and Gewanter, H. L. (1991). Psychosocial effects of juvenile rheumatic disease the family and peer systems as a context for coping. Arthr Care Res. 4, 123-130. doi: 10.1002/art.1790040304

Hassell, K. L. (2010). Population estimates of sickle cell disease in the U.S. Amer. J. Prevent. Med. 38(4 Suppl), S512-S521. doi: 10.1016/j.amepre.2009.12.022

Hechler, T., Kosfelder, J., Denecke, H., Dobe, M., Hübner, B., Martin, A., et al. (2008). Pain-related coping strategies in children and adolescents with chronic pain. Validation of a German version of the Paediatric Pain Coping Inventory (PPCI revised). Schmerz 22, 442-457. doi: 10.1007/s00482-008-0621-4

Higgins, J. P., and Green, S. (eds.). (2008). "Chapter 4: Searching for and selecting studies", in Cochrane Handbook for Systematic Reviews of Interventions, eds J. Higgins, J. Thomas, J. Chandler, M. Cumpston, T. Li, M. Page, and V. Welch (Chichester, UK: John Wiley and Sons, Ltd.), i-xxi. Available online at: http:// doi.wiley.com/10.1002/9780470712184.fmatter (accessed June 28, 2021).

Ho, L. Y. W. (2019). A concept analysis of coping with chronic pain in older adults. Pain Manage. Nurs. 20, 563-571. doi: 10.1016/j.pmn.2019.03.002

Huguet, A., Miró, J., and Nieto, R. (2009). The factor structure and factorial invariance of the Pain-Coping Questionnaire across age: evidence from community-based samples of children and adults. Eur. J. Pain. 13, 879-889. doi: 10.1016/j.ejpain.2008.10.004

Jacobson, C. J., Kashikar-Zuck, S., Farrell, J., Barnett, K., Goldschneider, K., Dampier, C., et al. (2015). Qualitative evaluation of pediatric pain behavior, quality, and intensity item candidates and the PROMIS pain domain framework in children with chronic pain. J. Pain. 16, 1243-1255. doi: 10.1016/j.jpain.2015.08.007

Jensen, M. P., Turner, J. A., Romano, J. M., and Karoly, P. (1991). Coping with chronic pain: a critical review of the literature. Pain 47, 249-283. doi: 10.1016/0304-3959(91)90216-K

Katter, J., and Greenglass, E. (2013). The influence of mood on the relation between proactive coping and rehabilitation outcomes. Canad. J. Aging. 32, 13-20. doi: $10.1017 /$ S071498081200044X

Keogh, E., and Eccleston, C. (2006). Sex differences in adolescent chronic pain and pain-related coping. Pain 123, 275-284. doi: 10.1016/j.pain.2006.03.004

Kim-Cohen, J., Moffitt, T. E., Caspi, A., and Taylor, A. (2004). Genetic and environmental processes in young children's resilience and vulnerability to socioeconomic deprivation. Child Dev. 75, 651-668. doi: 10.1111/j.1467-8624.2004.00699.x

King, S., Chambers, C. T., Huguet, A., MacNevin, R. C., McGrath, P. J., Parker, L., et al. (2011). The epidemiology of chronic pain in children and adolescents revisited: a systematic review. Pain 152, 2729-2738. doi: 10.1016/j.pain.2011.07.016

Kuo, B. C. H. (2011). Culture's consequences on coping: theories, evidences, and dimensionalities. J. Cross Cult. Psychol. 42, 1084-1100. doi: $10.1177 / 0022022110381126$

Landry, B. W., Fischer, P. R., Driscoll, S. W., Koch, K. M., Harbeck-Weber, C., Mack, K. J., et al. (2015). Managing chronic pain in children and adolescents: a clinical review. $P M \mho R$. 7, S295-315. doi: 10.1016/j.pmrj.2015.09.006

Lazarus, R. S., and Folkman, S. (1984). Stress, Appraisal, and Coping. New York, NY: Springer. 445.

Leung, L. (2012). Pain catastrophizing: an updated review. Indian J. Psychol. Med. 34, 204-217. doi: 10.4103/0253-7176.106012 
Lewandowski, A. S., Palermo, T. M., Stinson, J., Handley, S., and Chambers, C. T. (2010). Systematic review of family functioning in families of children and adolescents with chronic pain. J. Pain 11, 1027-1038. doi: 10.1016/j.jpain.2010.04.005

Logan, D. E., Conroy, C., Sieberg, C. B., and Simons, L. E. (2012). Changes in willingness to self-manage pain among children and adolescents and their parents enrolled in an intensive interdisciplinary pediatric pain treatment program. Pain 153, 1863-1870. doi: 10.1016/j.pain.2012.05.027

Lundh, A., and Gøtzsche, P. C. (2008). Recommendations by Cochrane Review Groups for assessment of the risk of bias in studies. BMC Med. Res. Methodol. 8, 22. doi: 10.1186/1471-2288-8-22

Marttinen, M. K., Santavirta, N., Kauppi, M. J., Pohjankoski, H., and Vuorimaa, H. (2018). Validation of the pain coping questionnaire in Finnish. Eur. J. Pain 22, 1016-1025. doi: 10.1002/ejp.1187

Miao, M., Zheng, L., and Gan, Y. (2017). Meaning in life promotes proactive coping via positive affect: a daily diary study. J. Happiness Stud. 18, 1683-1696. doi: 10.1007/s10902-016-9791-4

Miró, J., McGrath, P. J., Finley, G. A., and Walco, G. A. (2017). Pediatric chronic pain programs: current and ideal practice. Pain Rep. 2, e613. doi: 10.1097/PR9.0000000000000613

Moher, D., Liberati, A., Tetzlaff, J., Altman, D. G., and Group, T. P. (2009). Preferred reporting items for systematic reviews and meta-analyses: the PRISMA statement. PLoS Med. 6, e1000097. doi: 10.1371/journal.pmed.1000097

Moos, R. H., and Holahan, C. J. (2003). Dispositional and contextual perspectives on coping: toward an integrative framework. J. Clin. Psychol. 59, 1387-1403. doi: $10.1002 /$ jclp. 10229

Munn, Z., Peters, M. D. J., Stern, C., Tufanaru, C., McArthur, A., and Aromataris, E. (2018). Systematic review or scoping review? Guidance for authors when choosing between a systematic or scoping review approach. BMC Med. Res. Methodol. 18, 143. doi: 10.1186/s12874-018-0611-x

Pargament, K. I., Koenig, H. G., and Perez, L. M. (2000). The many methods of religious coping: Development and initial validation of the RCOPE. J. Clin. Psychol. 6, 519-543. doi: 10.1002/(sici)1097-4679(200004)56:4<519::aid-jclp6>3.0.co;2-1

Parker, J. C. (2020). Conceptual clarity in clinical bioethical analysis. J. Med. Philos. 45, 1-15. doi: 10.1093/jmp/jhz036

Parker, J. D. A., and Endler, N. S. (1992). Coping with coping assessment: a critical review. Eur. J. Pers. 6, 321-344. doi: 10.1002/per.2410060502

Patterson, J. M., and McCubbin, H. I. (1987). Adolescent coping style and behaviors: conceptualization and measurement. J. Adolesc. 10, 163-186. doi: 10.1016/S0140-1971(87)80086-6

Peres, M. F. P., and Lucchetti, G. (2010). Coping strategies in chronic pain. Curr. Pain Headache Rep. 14, 331-338. doi: 10.1007/s11916-010-0137-3

Perquin, C. W., Hazebroek-Kampschreur, A. A. J. M., Hunfeld, J. A. M., Bohnen, A. M., van Suijlekom-Smit, L. W. A., Passchier, J., et al. (2000). Pain in children and adolescents: a common experience. Pain 87, 51-58. doi: 10.1016/S0304-3959(00)00269-4

Peters, M., Godfrey, C., McInerney, P., Munn, Z., Tricco, A., and Khalil, H. (2019). “Chapter 11: Scoping reviews", in JBI Reviewer's Manual, 4th Edn. JBI. Available online at: https://synthesismanual.jbi.global (accessed June 29, 2020).

Pham, M. T., Rajić, A., Greig, J. D., Sargeant, J. M., Papadopoulos, A., and McEwen, S. A. (2014). A scoping review of scoping reviews: advancing the approach and enhancing the consistency. Res. Synth. Methods. 5, 371-385. doi: $10.1002 / j r s m .1123$

Pillai Riddell, R. R., Stevens, B. J., McKeever, P., Gibbins, S., Asztalos, L., Katz, J., et al. (2009). Chronic pain in hospitalized infants: health professionals' perspectives. J. Pain. 10, 1217-1225. doi: 10.1016/j.jpain.2009.04.013

Quartana, P. J., Campbell, C. M., and Edwards, R. R. (2009). Pain catastrophizing: a critical review. Expert Rev. Neurother. 9, 745-758. doi: 10.1586/ern.09.34

Reid, G. J., Gilbert, C. A., and McGrath, P. J. (1998). The Pain Coping Questionnaire: preliminary validation. Pain 76, 83-96. doi: 10.1016/S0304-3959(98)00029-3

Roberts, B. W., Caspi, A., and Moffitt, T. E. (2001). The kids are alright: growth and stability in personality development from adolescence to adulthood. J. Pers. Soc. Psychol. 81, 670. doi: 10.1037/0022-3514.81.4.670

Rosenstiel, A. K., and Keefe, F. J. (1983). The use of coping strategies in chronic low back pain patients: relationship to patient characteristics and current adjustment. Pain 17, 33-44. doi: 10.1016/0304-3959(83)9 0125-2

Roth, S., and Cohen, L. J. (1986). Approach, avoidance, and coping with stress. Amer. Psychol. 10-1037. doi: 10.1037/0003-066X.41.7.813

Rudolph, K. D., Dennig, M. D., and Weisz, J. R. (1995). Determinants and consequences of children's coping in the medical setting: conceptualization, review, and critique. Psychol. Bull. 118, 328-357. doi: 10.1037/0033-2909.118.3.328

Ryan-Wenger, N. M. (1990). Development and psychometric properties of the Schoolagers' Coping Strategies Inventory. Nurs. Res. 39, 344-349. doi: 10.1097/00006199-199011000-00005

Samulowitz, A., Gremyr, I., Eriksson, E., and Hensing, G. (2018). "Brave men" and "emotional women": a theory-guided literature review on gender bias in health care and gendered norms towards patients with chronic pain. Pain Res. Manag. 2018, 6358624. doi: 10.1155/2018/6358624

Schwartz, C. E. (2016). Introduction to special section on response shift at the item level. Qual. Life Res. 25, 1323-1325. doi: 10.1007/s11136-016-1299-1

Schwarzer, R., and Luszczynska, A. (2008). Reactive, anticipatory, preventive, and proactive coping: a theoretical distinction. Prev. Res. 15, 22-25.

Sharma, S., Ferreira-Valente, A., de, C., Williams, A. C., Abbott, J. H., Pais-Ribeiro, J., et al. (2020). Group differences between countries and between languages in pain-related beliefs, coping, and catastrophizing in chronic pain: a systematic review. Pain Med. 21, 1847-1862. doi: 10.1093/pm/pnz373

Singh, A., DasGupta, M., Simpson, P. M., and Panepinto, J. A. (2019). Use of the new pediatric PROMIS measures of pain and physical experiences for children with sickle cell disease. Pediatr. Blood Cancer 66, e27633. doi: $10.1002 /$ pbc. 27633

Skinner, E. A., Edge, K., Altman, J., and Sherwood, H. (2003). Searching for the structure of coping: a review and critique of category systems for classifying ways of coping. Psychol. Bull. 129, 216-269. doi: 10.1037/0033-2909.129.2.216

Skinner, E. A., and Zimmer-Gembeck, M. J. (2016). The Development of Coping : Stress, Neurophysiology, Social Relationships, and Resilience During Childhood and Adolescence. Switzerland: Springer. Available online at: http://search. ebscohost.com.subzero.lib.uoguelph.ca/login.aspx?direct=true $\& \mathrm{db}=$ nlebk $\&$ $\mathrm{AN}=1244917$ \&site $=$ ehost-live \&scope $=$ site

Spirito, A., Stark, L. J., Grace, N., and Stamoulis, D. (1991). Common problems and coping strategies reported in childhood and early adolescence. J Youth Adolesc. 20, 531-544. doi: 10.1007/BF01540636

Spirito, A., Stark, L. J., and Williams, C. (1988). Development of a Brief coping checklist for use with pediatric populations. J. Pediatr. Psychol. 13, 555-574. doi: 10.1093/jpepsy/13.4.555

Stanisławski, K. (2019). The coping circumplex model: an integrative model of the structure of coping with stress. Front. Psychol. 10, 694. doi: 10.3389/fpsyg.2019.00694

Stone, A. A., Greenberg, M. A., Kennedy-Moore, E., and Newman, M. G. (1991). Self-report, situation-specific coping questionnaires: what are they measuring? J. Pers. Soc. Psychol. 61, 648. doi: 10.1037/0022-3514.61.4.648

Strauss, M. E., and Smith, G. T. (2009). Construct validity: advances in theory and methodology. Annu. Rev. Clin. Psychol. 5, 1-25. doi: 10.1146/annurev.clinpsy.032408.153639

Sucharew, H. (2019). Methods for research evidence synthesis: the scoping review approach. J. Hosp. Med. 14, 416. doi: 10.12788/jhm.3248

Thastum, M., Zachariae, R., Schøler, M., and Herlin, T. (1999). A Danish adaptation of the Pain Coping Questionnaire for children: preliminary data concerning reliability and validity. Acta Paediatr. 88, 132-138. doi: 10.1111/j.1651-2227.1999.tb01070.x

Thompson, R. J., Gil, K. M., Keith, B. R., Gustafson, K. E., George, L. K., and Kinney, T. R. (1994). Psychological adjustment of children with sickle cell disease: stability and change over a 10-month period. J. Consult. Clin. Psychol. 62, 856-860. doi: 10.1037/0022-006X.62.4.856

Tobin, D. L., Holroyd, K. A., and Reynolds, R. V. (1984). User Manual for the Coping Strategies Inventory. Ohio University.

Tobin, D. L., Holroyd, K. A., Reynolds, R. V., and Wigal, J. K. (1989). The hierarchical factor structure of the coping strategies inventory. Cogn Ther Res. 13, 343-361. doi: 10.1007/BF01173478

Treede, R.-D., Rief, W., Barke, A., Aziz, Q., Bennett, M. I., Benoliel, R., et al. (2015). A classification of chronic pain for ICD-11. Pain 156, 1003-1007. doi: $10.1097 /$ j.pain. 0000000000000160 
Tricco, A. C., Lillie, E., Zarin, W., O’Brien, K. K., Colquhoun, H., Levac, D., et al. (2018). PRISMA Extension for Scoping Reviews (PRISMA-ScR): checklist and explanation. Ann. Intern. Med. 169, 467. doi: 10.7326/ M18-0850

Tutelman, P. R., and Webster, F. (2020). Qualitative research and pain: current controversies and future directions. Canad. J. Pain. 4, 1-5. doi: 10.1080/24740527.2020.1809201

Varni, J. W., Waldron, S. A., Gragg, R. A., Rapoff, M. A., Bernstein, B. H., Lindsley, C. B., et al. (1996). Development of the Waldron/Varni Pediatric Pain Coping Inventory. Pain 67, 141-150. doi: 10.1016/0304-3959(96)03077-1

Vervoort, T., Goubert, L., Eccleston, C., Bijttebier, P., and Crombez, G. (2006). Catastrophic thinking about pain is independently associated with pain severity, disability, and somatic complaints in school children and children with chronic pain. J. Pediatr. Psychol. 31, 674-683. doi: 10.1093/jpepsy/jsj059

Walker, L. S., Baber, K. F., Garber, J., and Smith, C. A. (2008). A typology of pain coping strategies in pediatric patients with chronic abdominal pain. Pain 137, 266-275. doi: 10.1016/j.pain.2007.08.038

Walker, L. S., Smith, C. A., Garber, J., and Van Slyke, D. A. (1997). Development and validation of the pain response inventory for children. Psychol. Assess. 9:392. doi: 10.1037/1040-3590.9.4.392

Westendorp, T., Verbunt, J. A., de Groot, I. J. M., Remerie, S. C., ter Steeg, A., and Smeets, R. J. E. M. (2017). Multidisciplinary treatment for adolescents with chronic pain and/or fatigue: who will benefit? Pain Pract. 17, 633-642. doi: 10.1111/papr.12495

Winter, S. S., Page-Reeves, J. M., Page, K. A., Haozous, E., Solares, A., Nicole Cordova, C., et al. (2018). Inclusion of special populations in clinical research: important considerations and guidelines. J Clin Transl Res. 4, 56-69. doi: 10.18053 /jctres.04.201801.003

Witter, J. P. (2016). The promise of patient-reported outcomes measurement information system-turning theory into reality: a uniform approach to patient-reported outcomes across rheumatic diseases. Rheum. Dis. Clin. 42, 377-394. doi: 10.1016/j.rdc.2016.01.007

Zamora, I., Williams, M. E., Higareda, M., Wheeler, B. Y., and Levitt, P. (2016). Brief Report: Recruitment and retention of minority children for autism research. J. Autism Dev. Disord. 46, 698-703. doi: 10.1007/s10803-0152603-6

Zimmer-Gembeck, M. J., and Skinner, E. A. (2016). "The development of coping: implications for psychopathology and resilience", in Developmental Psychopathology. (American Cancer Society), p. 1-61. Available online at: https://onlinelibrary.wiley.com/doi/abs/10.1002/9781119125556.devpsy410 (December 27, 2020).

Conflict of Interest: The authors declare that the research was conducted in the absence of any commercial or financial relationships that could be construed as a potential conflict of interest.

Publisher's Note: All claims expressed in this article are solely those of the authors and do not necessarily represent those of their affiliated organizations, or those of the publisher, the editors and the reviewers. Any product that may be evaluated in this article, or claim that may be made by its manufacturer, is not guaranteed or endorsed by the publisher.

Copyright (C) 2021 Nabbijohn, Tomlinson, Lee, Morrongiello and McMurtry. This is an open-access article distributed under the terms of the Creative Commons Attribution License (CC BY). The use, distribution or reproduction in other forums is permitted, provided the original author(s) and the copyright owner(s) are credited and that the original publication in this journal is cited, in accordance with accepted academic practice. No use, distribution or reproduction is permitted which does not comply with these terms. 